\title{
Magnetic fabrics in the Bjerkreim Sokndal Layered Intrusion, Rogaland, Southern Norway: Mineral Sources and Geological Significance
}

Andrea R. Biedermann ${ }^{a}$, Florian Heidelbach ${ }^{b}$, Mike Jackson $^{c}$, Dario Bilardelloc ${ }^{c}$, Suzanne A. McEnroe

${ }^{a}$ Department of Geology and Mineral Resources Engineering, Norwegian University of Science and Technology, Sem Sælands vei 1, 7491 Trondheim, Norway

${ }^{\mathrm{b}}$ Bayerisches Geoinstitut, University Bayreuth, Universitätsstrasse 30, 95440 Bayreuth, Germany

${ }^{c}$ Institute for Rock Magnetism, University of Minnesota - Twin Cities, 100 Union St SE, MN 55455

Minneapolis, USA

\section{Corresponding author}

Andrea R. Biedermann

Department of Geology and Mineral Resources Engineering

Norwegian University of Science and Technology

Sem Sælands vei 1

7491 Trondheim

Norway

andrea.regina.biedermann@gmail.com

+4740314154 


\begin{abstract}
Magnetic anisotropy can provide important information about mineral fabrics, and thus magmatic processes, particularly when it is known how multiple mineral species contribute to the anisotropy. It may also affect the direction of induced or remanent magnetization, with important consequences for paleomagnetic studies or the interpretation of magnetic anomalies. Here, we aim at describing the magnetic fabrics in the Bjerkreim Sokndal Layered Intrusion and identifying their carriers. Anisotropies of magnetic susceptibility and remanence were measured on samples covering different geographic locations and stratigraphic units within the Bjerkreim Sokndal Layered Intrusion. The intrusion is characterized by magmatic layering and has a synform structure, with strong foliation on the limbs. Detailed comparison between magnetic and mineral fabric shows that they are not necessarily coaxial, but the minimum susceptibility, and minimum anhysteretic remanence are generally normal to the foliation or the magmatic layering. The minimum susceptibility and anhysteretic remanence are associated with pyroxene (100) axes, and the maximum susceptibility and anhysteretic remanence are sub-parallel to the pyroxene [001] axes in layers MCU IVc and MCU IVe for which electron backscatter data are available. However, the paramagnetic anisotropy of pyroxene is too weak to explain the observed anisotropy. We propose that the magnetic anisotropy of magnetite-free specimens is carried by hemo-ilmenite exsolutions within pyroxene, in addition to pyroxene itself. When present, multi-domain magnetite dominates both the anisotropy of magnetic susceptibility and anhysteretic remanence, due to shape-preferred orientation and distribution anisotropy. The orientation of the magnetic fabric appears independent of carrier, due to their common deformation history, but the degree of anisotropy is stronger for magnetite-bearing specimens. The results of this study will facilitate future structural interpretations and may be used to correct for magnetization deflection.
\end{abstract}

Keywords: magnetic fabric, AMS, anisotropy of remanence, Bjerkreim Sokndal, layered intrusion, $\mathrm{CPO}$ 


\section{Introduction}

Magnetic anisotropy is a powerful tool to investigate mineral fabrics in a wide range of tectonic applications (Borradaile and Henry, 1997; Borradaile and Jackson, 2010; Hrouda, 1982; Martín-Hernández et al., 2004; Stacey, 1960; Tarling and Hrouda, 1993; Uyeda et al., 1963). Balsley and Buddington (1960) found that magnetic and mineral fabrics are parallel in granitic samples whose fabrics arise from magmatic flow or deformation. More recently, magnetic anisotropy has been found to reflect the preferred mineral orientation as defined by $\mathrm{X}$-ray and neutron diffraction in phyllosilicate-bearing rocks (Chadima et al., 2004; Hirt et al., 1995; Lüneburg et al., 1999; Siegesmund et al., 1995). Compared to other texture-determining techniques, electron backscatter diffraction (EBSD) has the advantage that the preferred orientation of various minerals and grain sizes can be determined in a polyphase aggregate (Prior et al., 1999). EBSD has therefore been used in recent magnetic fabric studies to determine which minerals carry the magnetic anisotropy (Bascou et al., 2002; Boiron et al., 2013). Biedermann et al. (2015) successfully modelled the paramagnetic anisotropy in mafic rocks based on EBSD data and single crystal properties.

In igneous rocks, magnetic anisotropy has been used as a proxy for lava flow dynamics, and to obtain information on emplacement processes (Archanjo et al., 1994; Archanjo and Bouchez, 1997; Brown et al., 1964; de Oliveira et al., 2010; Ellwood, 1978; Ferré et al., 2002; Halvorsen, 1974; Herrero-Bervera et al., 2001; Maes et al., 2007). However, conflicting results on whether the intermediate (Khan, 1962) or maximum (Wing-Fatt and Stacey, 1966) susceptibility axis is parallel to flow direction illustrates that it is important to understand which minerals carry the magnetic anisotropy, whether the carrier mineral(s) possess magnetocrystalline, shape or distribution anisotropy, and how minerals were aligned prior to interpreting AMS in terms of geological processes.

Mafic layered intrusions are of economic interest, as they can contain platinum group elements, chrome and nickel deposits (e.g. Charlier et al., 2015). Nevertheless, magnetic fabric studies in mafic - ultramafic intrusions are relatively rare (O'Driscoll et al., 2015). A possible reason for this is that interpreting magnetic fabrics in mafic rocks can be complicated by the presence of oriented ferromagnetic inclusions in mafic silicates (Lagroix and Borradaile, 2000). For example, Ferré et al. (2002) investigated magnetic fabrics in the mafic layered Insizwa sill, South Africa, and found that, whereas the magnetic lineation is parallel to mineral lineation, the magnetic and mineral foliations are generally perpendicular to each other. In contrast, Maes et al. (2008) observed that the magnetic fabric is parallel to magmatic layering in parts of the Insizwa sill, but does not show any systematic correlation in other parts. The mineralogy, and thus the magnetic properties, change 
within different units of the sill, which can also explain the seemingly inconsistent relationships between mineral and magnetic fabrics: magnetic anisotropy is either dominated by paramagnetic minerals or by magnetite (Maes et al., 2008). A variation in magnetic properties with petrographic layering has also been observed in other mafic layered intrusions (Ferré et al., 2009; Ferré et al., 2012). Thus, magnetic fabrics in these rocks can only be interpreted reliably after their origin is understood.

Both magnetic anomalies and paleomagnetic data can be affected by magnetic anisotropy, either directly (Clark, 1997; Clark and Schmidt, 1994), or because magnetic anisotropy causes NRM deflection, which has been observed in artificially deposited sediments (Anson and Kodama, 1987; King, 1955), Welsh slates (Fuller, 1960, 1963), hemo-ilmenite ore deposits at Allard Lake, Canada, whose AMS is dominated by hemo-ilmenite and NRM lies in or near the easy planes of hematite (Hargraves, 1959), and other synthetic and natural rock types (Bressler and Elston, 1980; Cogné, 1987; Huang et al., 2015; Lovlie and Torsvik, 1984; Tan and Kodama, 2002; Tarduno, 1990; Tauxe and Kent, 1984). In layered intrusions of the Duluth Complex, USA, NRM deflections of ca. $8.5^{\circ}$ have been observed (Beck Jr. and Lindsley, 1969). Also paleointensity estimates can be affected by magnetic anisotropy (Aitken et al., 1981; Rogers et al., 1979; Selkin et al., 2000b).

The present study will focus on the Bjerkreim Sokndal layered intrusion (BKS) in Rogaland, Southern Norway. This intrusion is characterized by strong petrographic layering (Wilson et al., 1996), and forms a syncline (Paludan et al., 1994). It is thus well suited to study magnetic fabrics in a layered mafic intrusion. The only previous study on magnetic fabrics in the BKS (Bolle et al., 2000), though extensive, focused on the uppermost part of the intrusion; ca. $80 \%$ of their 148 sites were in (quartz) mangerite or charnockite rocks. The possible implications that magnetic anisotropy has for the shape and intensity of magnetic anomalies and for paleomagnetic data, as well as the fact that magnetic anisotropy is a good proxy for mineral fabric, call for a more complete assessment of the magnetic fabrics in the BKS intrusion, particularly because the mangerite and charnockite rocks were formed later than the underlying cumulate series. Thus, characterizing and understanding the magnetic anisotropy in the cumulate series is important both for structural, paleomagnetic as well as magnetic anomaly studies.

The aim of this study is to (1) characterize the anisotropy of magnetic susceptibility (AMS) and anisotropy of remanence in the BKS, including their variations with location and mineralogy; (2) determine how the magnetic anisotropy relates to rock texture; and (3) identify how the various minerals contribute to the magnetic anisotropy. The results of this work can then be applied to 
future structural, paleomagnetic or magnetic anomaly studies in the BKS and similar layered intrusions.

\section{Theory}

Magnetic susceptibility $(k)$ is an intrinsic property of all materials and relates the magnetization $(M)$ induced by an applied field $(H)$ to the strength of that field, $\vec{M}=\boldsymbol{k} \vec{H}$, where $k$ is a second-order symmetric tensor. In single crystals, and consequently also in rocks with shapepreferred orientations (SPO) and/or crystallographic preferred orientations (CPO) of the minerals, magnetic susceptibility is generally anisotropic. AMS is described by the principal susceptibilities and their directions, i.e. the eigenvalues $k_{1} \geq k_{2} \geq k_{3}$, and eigenvectors of the tensor, which define the shape and orientation of the corresponding magnitude ellipsoid. Various parameters are used to describe the AMS degree and shape (e.g. Hrouda, 1982; Jelinek, 1981, 1984). In this study, the degree of anisotropy is described by the mean deviatoric susceptibility

$k^{\prime}=\sqrt{\left[\left(k_{1}-k_{\text {mean }}\right)^{2}+\left(k_{2}-k_{\text {mean }}\right)^{2}+\left(k_{3}-k_{\text {mean }}\right)^{2}\right] / 3}$, where $k_{\text {mean }}=\left(k_{1}+k_{2}+k_{3}\right) / 3$ is the mean magnetic susceptibility, and by the anisotropy ratio $P=k_{1} / k_{3}$, and the shape of the ellipsoid is described by

$U=\left(2 k_{2}-k_{1}-k_{3}\right) /\left(k_{1}-k_{3}\right)$

Note that $k^{\prime}$ quantifies the absolute deviation of the ellipsoid from sphericity; it depends directly on concentration of magnetic phases as well as on the strength of CPO/SPO, and is thus particularly suitable for anomaly modeling, as well as for understanding superposition of anisotropies from different mineral sources. $P$ and $U$ are dimensionless and not directly dependent on concentration, but are nevertheless influenced by mineralogical composition.

Minerals are classified as diamagnetic (e.g. pure plagioclase), paramagnetic (e.g. orthopyroxene and clinopyroxene) or ferromagnetic (s.l.) based on their magnetic properties. Ferromagnetic (s.l.) minerals are further subdivided into ferromagnetic (s.s., e.g. metallic iron), ferrimagnetic (e.g. magnetite, low-coercivity) and antiferromagnetic (e.g. hematite, high-coercivity) species. In the remainder of this paper we will use "ferromagnetic" in the broader generic sense. All minerals in a rock, ferromagnetic, paramagnetic or diamagnetic, when aligned, contribute to the AMS, whereas only ferromagnetic grains can contribute to anisotropy of remanence. In order to gain information about the mineral fabric it is useful to separate the components due to each mineral group. 
A number of separation techniques have been developed, including (1) statistical methods (Henry, 1983; Henry and Daly, 1983); (2) field- or temperature-dependence to either enhance or isolate specific components of the AMS (Ferré et al., 2004; Kelso et al., 2002; Martín-Hernández and Ferré, 2007; Martín-Hernández and Hirt, 2001, 2004; Pares and van der Pluijm, 2002; Rochette and Fillion, 1988; Rochette et al., 1983; Schmidt et al., 2007); and (3) thermal enhancement (Borradaile and Lagroix, 2000). A different approach is to measure the anisotropy of magnetic remanence (Borradaile and Jackson, 2010; Daly and Zinsser, 1973; Jackson and Tauxe, 1991; Jackson, 1991; Potter, 2004). Unlike magnetic susceptibility which can be dominated by the paramagnetic fraction, or large ferromagnetic grains that carry relatively little remanent magnetization, magnetic remanence is effectively carried by ferromagnetic grains of a certain size range. Various types of remanence anisotropies, e.g. the anisotropy of anhysteretic remanence (AARM; McCabe et al., 1985), anisotropy of isothermal remanence (AIRM; Daly and Zinsser, 1973; Stephenson et al., 1986) or anisotropy of thermal remanent magnetization (ATRM; Cogné, 1987, 1988) can be measured to assess the components of anisotropy carried by different minerals, e.g. magnetite or hematite. A major limitation for anisotropy of remanence methods is that antiferromagnetic minerals like hematite will not reach saturation in standard laboratory fields (Kodama and Dekkers, 2004). Weakfield magnetic remanence, e.g. AARM or ATRM can be described by a second-order tensor similar to AMS (Stacey and Banerjee, 1974). Strong-field magnetic remanence, i.e. AIRM imparted in high fields, however, is a nonlinear function of the applied field. Anisotropy of remanence is measured by either determining the intensity of the remanence parallel to the applied field in a set of orientations (Cox and Doell, 1967; McCabe et al., 1985) or by measuring the diagonal and off-diagonal elements of the tensor (parallel and transverse components of remanence) directly (Stephenson et al., 1986).

The rocks in this study contain two ferromagnetic minerals, magnetite and hemo-ilmenite, in addition to paramagnetic (pyroxenes) and diamagnetic (plagioclase) minerals. The magnetization behavior of these minerals is very different: magnetite has a lower coercivity and reaches saturation in low applied fields (a few hundred mT), whereas hemo-ilmenite has a higher coercivity, which depends on whether hematite or ilmenite act as host, and on how many generations of lamellae have developed during cooling (Robinson et al., 2004). The contribution of magnetite will be assessed by AARM measurements, and that of hemo-ilmenite by partially demagnetized AIRM.

\section{Geological Setting}

The Bjerkreim Sokndal intrusion (BKS) is a $230 \mathrm{~km}^{2}$ layered igneous intrusion, which was emplaced ca. $930 \mathrm{Ma}$ ago. It consists of three lobes, and the present study will focus on the Bjerkreim lobe which contains a cumulate series with 6 megacyclic units (MCU0, MCUla, MCUIb, MCUII, MCUIII, 
and MCUIV), overlain by acidic rocks (i.e. mangerite and quartz mangerite). Each MCU represents an individual magma influx followed by fractional crystallization, and is subdivided into several layers af, based on mineralogy (Wilson et al., 1996). The petrography and geochemistry of the BKS is well documented (Charlier et al., 2005; Duchesne, 2001; Duchesne and Charlier, 2005; McEnroe et al., 2000; Michot, 1960b, 1965; Robinson et al., 2001; Wilson et al., 1996), and an overview of the mineralogy for each layer is given in Figure 1. In addition to the classification based on cumulate minerals, McEnroe et al. (2009a) defined a specific layer within MCU IVe, MCU IVe', based on magnetic properties.

The major structure observed in the Bjerkreim lobe of the BKS is an isoclinal syncline, whose fold axis trends ca. $125^{\circ}$ and plunges ca. $35^{\circ}$ to the SE. Tectonic linear and planar fabrics overprint the igneous layering, and are defined by shape-preferred orientation of pyroxene and plagioclase, and of elongate aggregates of mafic minerals. Tectonic and igneous foliations are parallel in each limb of the syncline, but differ in the hinge zone, where the tectonic foliation parallels the axial plane of the fold. The fabric in the hinge zone has been described as dominantly linear. The lineation is weak in the structurally lower parts of the hinge zone, and becomes more intense in the higher parts of the cumulate series. A strong sub-vertical foliation has been described in both limbs of the fold, which is locally overturned at the north-eastern contact (Michot, 1960a; Paludan et al., 1994; Wilson et al., 1996). The depth to the floor of the intrusion and syncline has been estimated to $4 \mathrm{~km}-9 \mathrm{~km}$ based on gravity modelling, structural considerations, and a seismic profile (Deemer and Hurich, 1997; Paludan et al., 1994; Smithson and Ramberg, 1979).

Paludan et al. (1994) suggested that the formation of the syncline is related to gravitational instability, possibly accompanied by regional-scale folding, and also by shear along the limbs of the structure, an observation supported by new anisotropy data presented in this study. Bolle et al. (2000; 2002), instead relate the deformation exclusively to gravitational instability, either resulting from passive subsidence of the dense intrusive rocks, or diapiric emplacement of neighboring anorthosites. The same authors postulate a syn- to post-magmatic deformation temperature of $900^{\circ} \mathrm{C}$. Lineations and foliations within the syncline indicate a convergent flow pattern that is interpreted to result from a single event of solid-state deformation (Paludan et al., 1994; Bolle et al., 2000).

Lineations and foliations within the syncline show a convergent flow pattern, interpreted to result from a single event of solid state deformation. This deformation was caused by gravitational instability, leading to passive subsidence of the dense intrusive rocks, or diapiric emplacement of neighboring anorthosites (Bolle et al., 2000; Bolle et al., 2002; Paludan et al., 1994). Paludan et al. 
(1994) report a contemporaneous shear deformation along the limbs of the syncline in addition to the subsidence, and state that regional-scale folding may have contributed to the formation of the syncline.

The BKS attracted interest in the magnetic community as it generates a series of positive and negative magnetic anomalies (McEnroe et al., 1996; McEnroe et al., 2001; Rønning, 1995). The anomalies are related to varying amounts of the Fe-Ti oxides (hemo-)ilmenite and magnetite, whose relative abundance and composition change for different layers; hemo-ilmenite dominates in the primitive parts of the intrusion, whereas magnetite with various exsolution features becomes increasingly important in the more evolved parts (Brown and McEnroe, 2015; Duchesne, 1972; McEnroe et al., 2004a; McEnroe et al., 2001). Large changes in magnetic properties are observed across contacts, when the dominant magnetic mineral changes from hemo-ilmenite to magnetite or vice versa (McEnroe et al., 2009a). Both magnetite and hemo-ilmenite occur as large discrete grains, up to $0.5-1 \mathrm{~mm}$ size, or as exsolutions in pyroxenes. Magnetic force microscopy shows that large magnetite grains are multi-domain (MD), and magnetite exsolutions in clinopyroxenes are pseudosingle-domain (PSD) and MD grains, up to $30 \mu \mathrm{m}$ long and a few $\mu \mathrm{m}$ wide (Frandsen et al., 2004). Magnetite contents have been estimated to $0.4-5.2 \%$ throughout the intrusion (McEnroe et al., 2009a), and $0.2-6.1 \%$ for samples of the MCU IV unit close to Heskestad (McEnroe et al., 2004a), based on measurements of magnetic susceptibility. Magnetic susceptibility values reported by Brown and McEnroe (2015) translate to $0.04-4.6 \%$ magnetite for the cumulate series of the BKS.

Korneliussen et al. (2000) reports up to $20 \%$ ilmenite and up to $20 \% \mathrm{~V}$-bearing Ti-magnetite in parts of the intrusion.

Parts of MCU IVe' are associated with a strong negative anomaly of $-13,000 \mathrm{nT}$ at a height of $45 \mathrm{~m}$ above ground (McEnroe et al., 2004a; McEnroe et al., 2004b). This anomaly is caused by a stable and strong natural remanent magnetization (NRM) with an orientation roughly opposite to that of today's geomagnetic field, carried by lamellar magnetism of hemo-ilmenite (McEnroe et al., 2009a; McEnroe et al., 2001; Robinson et al., 2002, 2004). The NRM due to lamellar magnetism is characterized by (1) moderate to strong intensity, (2) large coercivity particularly for hematite-hosted lamellae, and (3) high thermal stability, and the rocks still carry the signature they acquired in the Proterozoic (Brown and McEnroe, 2015). The intensity of the lamellar magnetism NRM depends on the volume-concentration of the lamellae (McCammon et al., 2009; McEnroe et al., 2009a), and on the orientation of the lamellae with respect to the magnetizing field (Robinson et al., 2013). 


\section{Methods}

\subsection{Sample description}

Oriented specimens were collected during fieldwork or available from previous studies (e.g. Brown and McEnroe, 2015), and were selected so as to cover different units of the intrusion and various locations with respect to the fold (Table 1, cf. Figure 1). The new sample collection includes 258 specimens, with 95 drill cores from 29 sites, and 3 oriented blocks. From the existing collection, 104 specimens from 54 cores drilled at 20 sites and 9 oriented blocks were used. A special focus was put on the MCU IVe' layer, which generates the most prominent negative anomaly in the area. Because this anomaly disturbs the total magnetic field, compass readings for each drill core or block were double-checked by measuring the direction to the sun, or the known direction to another faraway point, when weather conditions did not allow sun corrections. Based on this, 61 orientations were corrected.

Initial sample characterization included determining density and mineralogy. Density was measured on a Mettler Toledo New Classic scale using Archimedes' principle. Polished $30 \mu \mathrm{m}$ thin sections were analyzed with both transmitted and reflected light microscopy, on an Olympus BX51 microscope. Pictures were taken with a ProgRes SpeedXTcore5 camera. Image analysis on scans of entire thin sections was used to estimate the percentage of opaque grains, i.e. magnetite, hemoilmenite and sulphides, using ImageJ. Image analysis was performed on 28 thin sections from 28 sites, mainly from the MCU IVe and MCU IVc units.

\subsection{Mineral fabrics}

CPOs of silicate and oxide minerals were measured with electron backscatter diffraction (EBSD) in a scanning electron microscope (SEM) at the Bayerisches Geoinstitut, University Bayreuth. The SEM was a Zeiss Gemini 1530 equipped with a Schottky emitter and an EBSD detection system from Oxford Instruments. Beam conditions were set to $25 \mathrm{keV}$ accelerating voltage and a beam current of about $2.3 \mathrm{nA}$ resulting in a measuring time of 0.18 seconds per data point. Highly polished sections of the cylinders previously used for the magnetic measurements were analyzed by measuring large areas (roughly $1 \mathrm{~cm}^{2}$ ) with a step size of 20 microns. In addition, smaller areas were measured with a step size of 0.55 to 0.8 microns on one specimen to investigate iron oxide exsolutions within pyroxene, and the orientation relationships of the exsolutions and the pyroxene. Phases chosen to index were magnetite, hemo-ilmenite, orthopyroxene (enstatite), clinopyroxene (diopside) and plagioclase (andesine) covering the major phases of the rocks. Concurrent chemical mapping with EDS was used to corroborate the correct indexing of the different phases and in addition revealed that in some specimens there were also significant amounts of apatite present. Analysis of CPO was 
partly hindered by the relative large grain size, especially for plagioclase, such that strong peaks from single grains dominate the pole figure (see below). For the main phases of interest (orthopyroxene, clinopyroxene, hemo-ilmenite and magnetite) the statistics of measurements were generally sufficient for a representative CPO. Data was processed in MTex 3.5 (Hielscher and Schaeben, 2008).

\subsection{Magnetic analyses}

\subsubsection{Rock magnetic properties}

A series of rock magnetic experiments was conducted on one or two specimens of selected sites (total 33 sites) to characterize the magnetic mineralogy: room-temperature hysteresis loops (12 specimens), alternating field (AF) demagnetization (37 specimens), acquisition of isothermal remanent magnetization (IRM; 2 specimens), high-temperature magnetic susceptibility (13 specimens) and low-temperature magnetic properties (6 specimens). Hysteresis loops were measured on a Princeton Measurements vibrating sample magnetometer (VSM) in fields up to 1.4 T. AF demagnetization was conducted on an Agico (Brno, Czech Republic) LDA5 demagnetizer or a DTech D-2000 Precision Instruments AF demagnetizer, and the remaining remanence was measured with an Agico JR6 spinner magnetometer or a 2G Enterprises (Mtn. View, CA, USA) RF SQUID superconducting rock magnetometer (SRM). Acquisition of IRM was determined using an ASCScientific (Carlsbad, CA, USA) IM-10-30 pulse magnetizer with a custom coil able to reach fields of $9 \mathrm{~T}$, and a 2G SRM. High-temperature magnetic susceptibility curves were measured on an Agico MFK1-A magnetic susceptibility bridge in a field of $200 \mathrm{~A} / \mathrm{m}$, frequency of $976 \mathrm{~Hz}$, and up to $700^{\circ} \mathrm{C}$. Lowtemperature magnetic properties were measured with a QuantumDesign (San Diego, CA, USA) magnetic property measurement system (MPMS). Strong-field magnetization was measured whilst cooling in a $2.5 \mathrm{~T}$ field, after which the field was turned off and the field-cooled (FC) remanence was measured during warming in zero field. Samples were then cooled in zero field (ZFC) and given a magnetization in $2.5 \mathrm{~T}$ isothermally at $20 \mathrm{~K}$ (LTSIRM), and the ZFC remanence curve was measured during warming in zero field. For low-temperature cycling of a room temperature IRM, remanence was measured from room temperature to $20 \mathrm{~K}$ and back to room temperature in zero field.

\subsubsection{Susceptibility and AMS}

Low-field magnetic susceptibility and its anisotropy were measured for all 361 specimens on an Agico MFK1-A magnetic susceptibility bridge, on standard-sized cores in a field of $200 \mathrm{~A} / \mathrm{m}$ and a frequency of $976 \mathrm{~Hz}$. Low-field AMS was determined either by measuring directional magnetic susceptibility in 15 orientations, or by rotating in 3 orthogonal planes (Jelinek, 1977, 1996). The results obtained with these two methods are indistinguishable for the 20 specimens on which both have been measured. To test whether the NRM has an effect on the low-field AMS, the AMS principal directions and anisotropy parameters of the same sample before and after AF demagnetization to 
$100 \mathrm{mT}$ and $200 \mathrm{mT}$ were compared for 8 samples, and were found to be the same within the error of the measurement. All low-field magnetic susceptibility data was corrected for effect of selfdemagnetization, which becomes important in specimens with magnetic susceptibility larger than 0.1 (SI; e.g. Clark, 2014). High field AMS was determined by measuring hysteresis loops in 36 different orientations in three orthogonal planes (Ferré et al., 2004; Kelso et al., 2002). Cubes with 1 $\mathrm{cm}$ or $5 \mathrm{~mm}$ side length were used in order to minimize artefacts due to shape, and two cubes were measured for each specimen to assess reproducibility.

\subsubsection{Anisotropy of remanence}

A total of 97 remanence anisotropy experiments were conducted, with the aim to characterize the anisotropy of different ferromagnetic minerals. Anisotropy of anhysteretic remanence (AARM, 57 specimens) and partial anhysteretic remanence (ApARM, 10 specimens) were measured by applying a DC bias field during AF decay. DC bias fields of $0.1 \mathrm{mT}$ were applied over the AF ranges of $100 \mathrm{mT}-0 \mathrm{mT}$, and $190 \mathrm{mT}-120 \mathrm{mT}$ for AARM and ApARM, respectively. A 9-position measurement scheme was used initially, and later replaced by a 3-position measurement scheme, because the full-vector calculation based on 3 positions yielded results that were indistinguishable from those of the parallel-component calculation using 9 measurements.

Anisotropy of partially demagnetized IRM (ApIRM, 22 specimens) was determined by magnetizing the specimens in 9 directions using a $2 \mathrm{G}$ pulse magnetizer in a field of $1 \mathrm{~T}$ and then removing the low-coercivity component by AF demagnetization at $150 \mathrm{mT}$. Each directional magnetization was measured on a 2G SRM. Because the specimens are so strongly magnetic, we did not attempt to measure the full AIRM, which was expected to be higher than the upper measurement limit of the $2 \mathrm{G}$.

Anisotropy of thermal remanence (ATRM) and partially demagnetized thermal remanence (ApTRM) was measured on a set of 8 specimens. They were heated to $625^{\circ} \mathrm{C}$, i.e. above the ordering temperature of hemo-ilmenite (up to $\sim 60{ }^{\circ} \mathrm{C}$, depending on composition) as shown by McEnroe et al. (2002) and McEnroe et al. (2009a), and subjected to a $50 \mu$ T field during cooling. Full TRM and 'hard TRM' (thermal remanence demagnetized in an AF field of $150 \mathrm{mT}$ ) were imprinted along three perpendicular directions and measured on a 2G SRM. Data was processed with the software package available at the Institute for Rock Magnetism, University of Minnesota. 


\section{Results}

\subsection{Optical microscopy}

The rocks consist of various amounts of plagioclase, orthopyroxene, clinopyroxene, hemoilmenite, magnetite, sulfides and apatite (Figure 2). In particular the pyroxenes are strongly deformed, but also the exsolution lamellae in plagioclase indicate deformation. Orthopyroxene and clinopyroxene contain exsolutions of hemo-ilmenite with two distinct orientations, but elongated primarily along the pyroxenes' [001] axes. Clinopyroxene contains additional exsolutions of magnetite. The amount of opaque grains, including magnetite, hemo-ilmenite and sulphides, as determined by image analysis varies from 2 to around $20 \%$, and are commonly around $10 \%$ (cf. Table A). Note that specimens with high magnetic susceptibility and NRM were chosen to produce thin sections. Because image analysis was performed on one cross-section, whereas opaque grains are heterogeneously distributed in the sample, these values should be taken as an approximate estimate rather than the true amount of opaques in the specimen.

\subsection{Mineral fabrics}

The rock texture is characterized by layering of mafic and felsic minerals, as well as CPO of the different mineral phases. EBSD of 8 specimens from the MCU IVc and MCU IVe' layers shows strong preferential alignment of orthopyroxene and clinopyroxene, whose (100) axes are approximately normal to the layering, which is sub-vertical in the east of the Bjerkreim lobe (Paludan et al., 1994; Figure 3). Orthopyroxene fabrics are stronger and better defined than clinopyroxene fabrics. The presence of several high maxima in the pyroxene orientation density function in some specimens indicates that only a small number of grains had been measured. The plagioclase fabric is weaker than the pyroxene fabric, except for two specimens, for which only a small number of large grains had been measured. The ferromagnetic minerals magnetite and hemo-ilmenite show rather uniform orientation density functions, except in site BK2015_26, where the hemo-ilmenite (0001) plane is parallel to foliation (Figure A, Supplementary Material).

Detailed investigation of the exsolutions within pyroxenes of specimen BK2015_4_1b, as determined by EBSD, shows that orthopyroxene contains hemo-ilmenite lamellae, mainly with hemoilmenite (0001) axes parallel to the orthopyroxene (100) axes (i.e. $(0001) / /(100))$ and a minor fraction having (11-20)//(010). Clinopyroxenes contain enstatite and hemo-ilmenite $(100) / /(0001)$ and magnetite exsolutions extended in the (010) plane of diopside/(110) of magnetite. The orientation relationships are: $\mathrm{Cpx}(100) / / \mathrm{Opx}(100) / / \mathrm{Hem}-\mathrm{IIm}(0001) / / \mathrm{Mag}(111)$, and Cpx(010) // Opx(010) // Hem-IIm(10-10) // Mag(110), and Cpx[001] // Opx(001) // Hem-IIm(11-20). 


\subsection{Rock magnetism and magnetic anisotropy}

\subsubsection{Rock magnetic properties}

Mean magnetic susceptibilities vary over several orders of magnitude, from $5^{*} 10^{-4}(\mathrm{SI})$ to $0.23(\mathrm{SI})$. Hysteresis loops of the new samples are similar to what has been described previously (McEnroe et al., 2009a). AF demagnetization reveals three distinct groups of specimens (Figure 4): (1) Most specimens $(n=33)$ show a large decrease of magnetization in alternating fields up to $20 \mathrm{mT}$, generally followed by a slower decay. In particular, specimens with strong initial magnetization (20$40 \mathrm{~A} / \mathrm{m}$ ) lose $90 \%$ of their remanence below $60 \mathrm{mT}$. A magnetization of up to $1 \mathrm{~A} / \mathrm{m}$ remains after the maximum AF demagnetization step of $200 \mathrm{mT}$. This behavior is typical for specimens from layers $d, e$, and $f$, which contain magnetite in addition to (hemo-)ilmenite. Remanence decay in low field is however also observed in some specimens from layers a and c, e.g. BK106. (2) The second group of specimens $(n=10)$ reacts little to AF demagnetization below $50 \mathrm{mT}$, followed by a drop in magnetization between 50 and $120 \mathrm{mT}$, and ca. $5 \%$ of the magnetization remains after the maximum demagnetization step. These specimens belong to the clayers of different MCUs; and (3) specimens from sites BK31, BK110 and BK111 (a layers) do not demagnetize below ca. 100 mT, and up to $70 \%$ of the magnetization remains at $200 \mathrm{mT}$. This behavior is similar to that reported by Brown and McEnroe (2015).

Additional experiments were performed to further investigate Group (1), particularly to identify the high-coercivity component, which remains after AF demagnetization to $200 \mathrm{mT}$. In IRM acquisition experiments, the remanence appears to saturate at ca. $300 \mathrm{mT}$ and remains stable up to 9 T (Figure 5). Magnetic susceptibility vs high-temperature curves show a number of different behaviors, but all have (dis)ordering (Curie) temperatures of $579{ }^{\circ} \mathrm{C} \pm 4^{\circ} \mathrm{C}$ during heating, and $581 \pm$ $3{ }^{\circ} \mathrm{C}$ upon cooling. The behavior at lower temperatures is not always reversible (Figure 6).

Measurement of synthetic magnetite and hematite standards in an Argon atmosphere consistently resulted in Curie and Néel temperatures of $590^{\circ} \mathrm{C}$ and $\sim 700^{\circ} \mathrm{C}$, respectively (N.S. Church, pers. comm.), indicating that the temperature calibration is $\sim 10{ }^{\circ} \mathrm{C}$ too high when compared to the known stoichiometric magnetite Curie temperature of $580^{\circ} \mathrm{C}$ and a stoichiometric hematite Néel temperature of $685^{\circ} \mathrm{C}$. Whereas more work is needed to adjust the temperature calibration for rock magnetic studies, for the purpose of this investigation, it can be assumed that the true Curie temperatures are likely $10{ }^{\circ} \mathrm{C}$ lower than measured, i.e. around $570^{\circ} \mathrm{C}$. The observed Curie temperatures are indicative of magnetite with very minor Ti-substitution. Hematite with about $12 \%$ Ti substitution would have a similar Néel temperature (e.g. Hunt et al., 1995), however, its contribution to magnetic susceptibility is negligible compared to that of magnetite. 
At low temperature, a Néel transition can be observed at $\sim 55 \mathrm{~K}$ (Figure 7 ) in the strong-field magnetization curve. It is seen in all specimens measured, but most prominently in BK2015_17 and BK2015_26. The ZFC and FC remanence curves show two transitions (defined by their steepest slopes) at $28 \mathrm{~K}$ and between 97 and $103 \mathrm{~K}$. Three transitions are generally observed during lowtemperature cycling of a room temperature remanence: a minor change at $50 \pm 3 \mathrm{~K}$, and much larger ones at 95 $\pm 3 \mathrm{~K}$ and 123 $\pm 3 \mathrm{~K}$ (Figure 7). Specimen BK2015_17_1b appears to have an additional transition at ca. $104 \mathrm{~K}$. The transitions at $95 \mathrm{~K}$ and $123 \mathrm{~K}$ are interpreted as Verwey transitions due to magnetite (Muxworthy and McClelland, 2000; Verwey, 1939). A Verwey transition temperature around $123 \mathrm{~K}$ indicates pure stoichiometric magnetite. The transition temperature can be lowered due to e.g. maghemitization (i.e. oxidation) or substitution (Dunlop and Özdemir, 1997). The lowest transition, near $50 \mathrm{~K}$, may be associated with the ilmenite host of the hemo-ilmenite (Ishikawa and Akimoto, 1958; Ishikawa, 1962; Stickler et al., 1967), or with MD magnetite (Hirt et al., 2006; Moskowitz et al., 1998; Muxworthy, 1999). The Néel temperature of ilmenite in hemo-ilmenite has been observed between $57 \mathrm{~K}$ and $60 \mathrm{~K}$ (Ishikawa, 1962; McEnroe et al., 2009b; McEnroe et al., 2002), so the transition observed in the strong-field magnetization curve at $55 \mathrm{~K}$ is almost certainly due to ilmenite.

\subsubsection{AMS}

Low-field magnetic anisotropy is strongly significant in all 361 specimens ( $F$-value over 100; 3.48 significance threshold; Table A, Supplementary Material). The anisotropy degree $P$ ranges from 1.06 to 3.59, with the largest $P$-values in the magnetite-rich sites BK44, BK47 (d-layer), and some high $P$ values in the IVe' layer (BK2015_2, BK2015_17, BK2015_14). The mean deviatoric susceptibility, $k^{\prime}$, varies between $3.4 * 10^{-5}(\mathrm{SI})$ and $0.10(\mathrm{SI})$, or between $2.3 \%$ and $50.2 \%$ of the mean magnetic susceptibility. The highest values for $k^{\prime}$ are observed in the same sites that display large $P$-values. Anisotropy parameters of specimens with high mean susceptibility have to be taken with caution due to the large effect of self-demagnetization. The shape of the AMS ellipsoid varies between highly prolate $(U=-0.92)$ to highly oblate $(U=0.84)$, but most specimens, especially those with high mean magnetic susceptibilities, have prolate AMS ellipsoids.

The directions of the principal magnetic susceptibility axes are generally well grouped for specimens of the same site and sites located closely (Figure 8), particularly in the eastern part of the layered intrusion. More spread within sites and between adjacent sites is observed in the hinge zone, where anisotropy is weaker, and towards the west of the intrusion. Principal magnetic susceptibility directions vary with geographic location, but seem independent of stratigraphic height, and mineralogy. 
High-field anisotropy measured on the VSM yielded inconsistent results for different specimens from the same site. This suggests that the small cubes measured are not representative of the rocks. Larger cubes could not be used as the samples were strongly magnetic.

\subsubsection{Anisotropy of remanence}

Anisotropy of anhysteretic remanence describes the isolated anisotropy due to remanencecarrying magnetite with coercivity up to $100 \mathrm{mT}$. AARM was measured on 57 specimens and is significant for all but nine of these (Table B, Supplementary Material). Particularly, AARM is significant in 41 out of 43 measured specimens showing a remanence decay in low AF fields (Group (1)). This includes specimens from layers $d-f$, but also some from layers a or $c$ that contain only small amounts of magnetite. Seven out of 11 specimens from Group (2) have a significant AARM. It is not significant for specimens of Group (3). Mean anhysteretic remanence varies from $1.3 * 10^{-6}$ to $7.3^{*} 10^{-5}$ $\mathrm{Am}^{2} / \mathrm{kg}\left(3.6^{*} 10^{-3}\right.$ to $\left.0.24 \mathrm{~A} / \mathrm{m}\right)$. The degree of anisotropy ranges from $P=1.15$ to 3.62 , or $k^{\prime}=9.7^{*} 10^{-8}$ $\mathrm{Am}^{2} / \mathrm{kg}$ to $2.9 * 10^{-5} \mathrm{Am}^{2} / \mathrm{kg}\left(2.7 * 10^{-4}\right.$ to $\left.2.9 * 10^{-2} \mathrm{~A} / \mathrm{m}\right)$, corresponding to 5.8 to $53.7 \%$ of the mean anhysteretic remanence. The shape of the AARM ellipsoid is dominantly prolate, with only three specimens displaying an oblate shape; $U$ varies between -0.91 and 0.30 . The AARM has a similar orientation as the low-field AMS in the majority of specimens. An exception is BK45, in which the minimum AARM is parallel to the maximum susceptibility. ApARM is not significant in any of the specimens on which it was measured. Thus, no anisotropy is carried by grains with coercivities between $120 \mathrm{mT}$ and $190 \mathrm{mT}$.

The ApIRM describes the anisotropy of the remanence-carrying minerals in the 150-1000 mT coercivity range. It was measured on 22 specimens and is significant in 12 of these, however, not as well defined as the AMS or AARM, as the confidence ellipses are larger. ApIRM is significant in 8 of 15 measurements for Group (1), 4 of 5 measurements for Group (2). In Group (3), 2 specimens had been measured, and none displays a significant ApIRM. The mean partial IRM ranges from $1.1 * 10^{-9} \mathrm{Am}^{2} / \mathrm{kg}$ to $1.1 * 10^{-8} \mathrm{Am}^{2} / \mathrm{kg}\left(3.6^{*} 10^{-6} \mathrm{~A} / \mathrm{m}-3.5^{*} 10^{-5} \mathrm{~A} / \mathrm{m}\right)$, and is orders of magnitude weaker than the mean anhysteretic remanence, thus explaining the lower confidence. The ratio between maximum and minimum partial IRM is around 1.1-1.2 in the majority of specimens, but in specimen BK2015_2_1c, it is as high as 4.7. The minimum and maximum partial IRMs appear switched with respect to the minimum and maximum principal susceptibilities or AARMs in most specimens of Group (1) (BK2015_2,_5,_14,_18,_20), but can be coaxial in others (BK2015_4,_17). In Group (2), ApIRM can be, but is not necessarily coaxial to the AMS and AARM. In site BK45, the ApIRM principal axes are close to those of the AARM, with the minimum pIRM sub-parallel to the maximum susceptibility. This may indicate an inverted AMS fabric. 
The ATRM should be dominated by magnetite, and is significant in all but two of eight measured specimens. The anisotropy left after partial AF demagnetization should be carried by hemo-ilmenite, and is significant in three specimens. The mean TRM varies from $1.2^{*} 10^{-4} \mathrm{Am}^{2} / \mathrm{kg}$ to $2.7 * 10^{-4} \mathrm{Am}^{2} / \mathrm{kg}\left(1.5^{*} 10^{-2} \mathrm{~A} / \mathrm{m}-2.2 * 10^{-2} \mathrm{~A} / \mathrm{m}\right)$ and the mean pTRM from $4.7 * 10^{-6} \mathrm{Am}^{2} / \mathrm{kg}$ to $7.2 * 10^{-6}$ $\mathrm{Am}^{2} / \mathrm{kg}\left(3.9 * 10^{-1} \mathrm{~A} / \mathrm{m}-8.4 * 10^{-1} \mathrm{~A} / \mathrm{m}\right)$. The degree of anisotropy is stronger for the ATRM $(P=2.31-$ $3.26 ; \mathrm{k}^{\prime}=3.9 * 10^{-5} \mathrm{Am}^{2} / \mathrm{kg}-1.2 * 10^{-4} \mathrm{Am}^{2} / \mathrm{kg}$ or $31.6-49.6 \%$ of the mean TRM) than the ApTRM ( $P=$ $1.47-1.94 ; k^{\prime}=1.2 * 10^{-6} \mathrm{Am}^{2} / \mathrm{kg}-1.4 * 10^{-6} \mathrm{Am}^{2} / \mathrm{kg}$ or 16.1 to $28.8 \%$ of the mean pTRM). As both AARM and ATRM characterize anisotropy of magnetite, it is expected that they are coaxial. This is the case for some sites, but the intermediate and maximum axes are switched in other sites, even though the remanence ellipsoids do not have oblate shapes. Similarly, if ApIRM reflects hemoilmenite anisotropy as does the ApTRM, their principal axes should be parallel, which is not observed in the two specimens where both anisotropies are significant. It remains an open question whether laboratory remanence (ApTRM or ApIRM) adequately reflects the remanence carried by lamellar magnetism, as the latter is a chemical remanence, formed during exsolution of the lamellae (Robinson et al., 2004), and not a TRM. Additionally, thermal remanence results have to be interpreted with caution as alteration during heating cannot be excluded. They will thus not be discussed further.

\section{Discussion}

The main goal of the following discussion is to determine which mineral(s) contribute to or dominate the magnetic fabrics in each layer of the BKS intrusion. To achieve this, we will first discuss the magnetic mineralogy, i.e. determine which ferromagnetic minerals have been identified in microscopy and rock magnetic analyses. This will be followed by a comparison of macroscopic fabric, CPO, SPO and magnetic fabric orientation, before it will be possible eventually to identify the carriers of the magnetic fabric.

\subsection{Magnetic mineralogy}

Two types of oxides, magnetite and hemo-ilmenite, have been observed in different amounts in thin sections and from rock magnetic analyses, in accordance with results from previous studies on the BKS (Brown and McEnroe, 2015; Duchesne, 1972; McEnroe et al., 1996; McEnroe et al., 2004a; McEnroe et al., 2001). Low- and high-temperature magnetic properties, as well as AF demagnetization curves confirm the presence of two oxides, magnetite and hemo-ilmenite, and the two Verwey transitions are attributed to two types of magnetite. Magnetite dominates the bulk magnetic properties in layers $\mathrm{d}, \mathrm{e}$, and $\mathrm{f}$. According to the mineralogical classification, layers a and $\mathrm{c}$ contain only hemo-ilmenite as oxide mineral, however, rock magnetic experiments reveal that small 
amounts of magnetite are present in some sites, as has also been described by McEnroe et al. (2009a). Mean magnetic susceptibility increases with density, following one of two distinct trends (Figure 9a), reflecting magnetic properties dominated by magnetite or hemo-ilmenite, respectively. Additional variation is associated with the amount of pyroxene present in each specimen. Also AMS parameters vary depending on which oxide dominates; both $P$ and $k^{\prime}$ are higher for magnetitebearing samples, and lower if hemo-ilmenite is the only oxide present. The AMS shape $U$ is more prolate in samples dominated by magnetite (Figure $9 b-f)$.

When present, magnetite with its strong magnetization completely dominates the bulk magnetic susceptibility. Therefore, the magnetite concentration can be estimated from the mean magnetic susceptibility or anhysteretic remanence. Clark (1997) provides the following formula to estimate the volume fraction of magnetite:

$$
x(\text { vol. } \%)=k_{\text {mean }} / 0.0347,
$$

for magnetite fractions of a few percent, based on average empirical relationships (Puranen, 1989). According to this linear relationship, the specimens presented here contain between $0.02 \%$ and 6.5 $\%$ magnetite. Slightly higher values are obtained when using Thompson and Oldfield (1986)'s typical magnetic susceptibility values for MD (2.8 SI) and single-domain (SD; $2.4 \mathrm{SI}$ ) magnetite; $0.02 \%$ - 8.1 $\%$, and $0.02 \%$ - $9.4 \%$, respectively. However, significant deviations from this linear relationship were observed for > 10 vol.\% magnetite, and the intrinsic magnetic susceptibility of pure magnetite ore can vary between $13 \mathrm{SI}$ for fine-grained magnetite, and up to $130 \mathrm{SI}$ for very coarse, well-crystallized magnetite (Clark, 1997). Thus, values higher than a few \% have to be interpreted with caution. Earlier studies report susceptibilities between 0.07 to 0.12 (McEnroe et al., 1996) or 7*10 ${ }^{-3}$ to 0.17 (McEnroe et al., 2004a) in the Heskestad area, which corresponds to a maximum of $6.1 \%$ magnetite; up to 1 (SI; McEnroe et al., 2001) in ore bodies associated with the intrusion and between $1 * 10^{-4}$ and 0.2 (SI) throughout the intrusion (McEnroe et al., 2009a), which leads to similar estimates. Brown and McEnroe (2015) show susceptibilities between $2.0^{*} 10^{-3}$ and $7.6^{*} 10^{-2}$ in the a layers, $1.6 * 10^{-3}$ to $2.5 * 10^{-2}$ in the b layers, $1.4 * 10^{-3}-1.6 * 10^{-2}$ in c layers, $2.5 * 10^{-2}$ to 0.16 in layer $d, 1.7 * 10^{-2}$ to $8.3 * 10^{-2}$ in e (including $e^{\prime}$ ), and $7.4 * 10^{-2}$ to 0.12 in layer f. This corresponds to $0.06-2 \%, 0.04-0.7 \%, 0.04-$ $0.5 \%, 0.7-4.6 \% 0.5-3.8 \%$ and $2.1-3.4 \%$ magnetite in layers $a, b, c$, d, e and f, respectively. More definitive concentration calculations based on saturation magnetization $\left(M_{s}\right)$, which is independent of domain state, yield estimates consistent with the range of magnetic susceptibilitybased estimates, for the sites where hysteresis data is available: $M_{s}$ ranges from 0.5 to $5 \mathrm{Am}^{2} / \mathrm{kg}$, corresponding to $0.6 \%$ to $6 \%$ magnetite by mass. However, variation is observed between different subsamples of the same specimen. Image analysis indicates typically around $10 \%$ opaque grains, 
which can be taken as an upper limit of the amount of magnetite. This is consistent with estimates based on magnetic properties, and lies within the range given by Korneliussen et al. (2000).

The remanence-carrying magnetite fraction can be estimated by using representative values for ARM susceptibility of $100 \mathrm{\mu m}^{3} / \mathrm{kg}$ (MD magnetite) and $800 \mathrm{\mu m}^{3} / \mathrm{kg}$ (SD magnetite), respectively (Thompson and Oldfield, 1986). This yields a maximum of $1 \mathrm{wt} . \%$ magnetite, which is much lower than the magnetite fraction calculated from magnetic susceptibility or saturation magnetization. This can be explained by (1) the magnetite grains in the BKS samples are less efficient in acquiring remanence than the reference material used by Thompson and Oldfield (1986), or (2) only a small part of the magnetite present in the samples carries remanence, while the majority of magnetite is MD and contributes only to magnetic susceptibility. The latter is in agreement with Frandsen et al. (2004), who describe two magnetite fractions; large MD grains on a $100 \mu \mathrm{m}$ scale, and elongated PSD grains on the order of $30 \mu \mathrm{m}$ long and $<5 \mu \mathrm{m}$ wide. Thus, three magnetic carriers can be identified: MD magnetite, PSD magnetite and hemo-ilmenite.

\subsection{Macroscopic fabric, CPO and magnetic anisotropy}

The macroscopic foliation and lineation are defined by (1) igneous layering, i.e. mafic and felsic layers, (2) SPO of aggregates of mafic minerals, and (3) preferred alignment of individual mineral phases (Bolle et al., 2000; Paludan et al., 1994). Felsic and mafic layers are observed on an outcrop and sample scale. Image analysis shows that opaque grains, and thus magnetite, display SPO and are concentrated in specific planes (Figure 10). The EBSD data presented here show CPOs in agreement with the macroscopic fabric. The CPOs are strongest for orthopyroxene, with (100) planes parallel to foliation. Clinopyroxene fabrics are weaker, but the grouping of (100) has a similar orientation to the orthopyroxene (100). Plagioclase shows a weak CPO, generally with (010) parallel to foliation. Similar preferred orientations of plagioclase with respect to macroscopic fabric have been reported in the Bushveld layered intrusion (Feinberg et al., 2006), the Stillwater Complex (Selkin et al., 2000a), and the Oklahoma anorthosite (Seront et al., 1993).

A comparison between AMS, AARM and CPO shows a striking similarity in the direction of the minimum susceptibility, minimum anhysteretic remanence and the grouping of orthopyroxene (100) axes. The minimum susceptibility is also associated with plagioclase (010) and clinopyroxene (100). Maximum susceptibility and remanence correlate best with the preferred orientation of orthopyroxene (001) axes, and to a lesser extent with clinopyroxene [001] axes and plagioclase (001) axes (Supplementary Material, Figure A). This is particularly true for samples from the IVe and IVc layers for which EBSD data are available. Because the orientation of the magnetic fabric appears to be independent of MCU layer, similar relationships can be assumed throughout the intrusion. 
Magnetic anisotropy, both AMS and AARM, loosely reflects the macroscopic foliation and lineation, with the minimum susceptibility being approximately normal to foliation (Figure 11). A detailed comparison shows, however, deviations from this general trend for some sites, especially in the northeast of the intrusion in terms of lineations. Possible reasons for this are (1) that the magnetic field is deviated due to the strong anomalies in the region, so that compass-based orientations from previous fabric studies may need to be corrected for, (2) specimens are affected by small-scale heterogeneities in texture, or (3) that the AMS fabric is not parallel to the texture. Charlier et al. (2005) reported a faster cooling rate in the Teksevatnet area, i.e. the northeastern part of the intrusion, and a more orthocumulate-like texture. To understand whether the magnetic lineation and foliation are expected parallel to mineral fabric, it is important to know which mineral(s) carry the AMS.

\subsection{Carriers of anisotropy}

Even though the bulk magnetic properties are clearly dominated by magnetite, or hemo-ilmenite in magnetite-free specimens, this is not necessarily the case for AMS. It has been shown repeatedly that paramagnetic minerals may be responsible for anisotropy in rocks whose bulk magnetic susceptibility is dominated by ferromagnetic minerals (Borradaile, 1987; Borradaile et al., 1985/86; Hirt et al., 1995; Hounslow, 1985; Rochette, 1987; Rochette et al., 1992; Rochette and Vialon, 1984). Specifically in a mafic layered intrusion, Maes et al. (2008) reported that the AMS is carried by paramagnetic minerals in some parts of the intrusion, and by magnetite in other parts. For a complete understanding of the magnetic fabrics, it is thus essential to carefully evaluate which mineral(s) is carries the anisotropy.

Potential carriers need to comply with the following observations:

- mineralogy as observed in thin sections, and magnetic mineralogy as determined from rock magnetic experiments, including which type of remanence anisotropy they carry

- correlation between magnetic fabric and rock texture, and orientation of the magnetic fabric independent of MCU layer, but with smaller degree of anisotropy in magnetite-free samples.

- similar orientation of AMS and AARM, i.e. both controlled by the same grains or by different grains that give rise to the same magnetic fabric

In the following sections, the expected magnetic fabrics of all relevant minerals and their potential as AMS carriers will be discussed. 


\subsubsection{Expected AMS and anisotropy of remanence of main minerals in the BKS}

Main minerals that may contribute to AMS in the BKS include plagioclase, pyroxene, and hemoilmenite and MD magnetite discrete grains. The magnetic susceptibility and AMS of plagioclase is weak and can thus be neglected (Biedermann et al., 2016).

In clinopyroxene crystals, the maximum and minimum susceptibilities lie within the (010) plane and are tilted $\pm 45^{\circ}$ to the [001] axis. In single crystals of orthopyroxene, the maximum susceptibility is parallel to the (001) axis, and the minimum parallel to (010), and the AMS ellipsoid has a prolate shape ( $U$ varies from -0.2 to -0.7; Biedermann et al., 2015; cf. Figure 11). These singlecrystal properties can explain the correlation between maximum susceptibility and orthopyroxene (001) axes in the BKS specimens. Anisotropic physical properties of rocks can be modelled provided that they depend on the minerals' bulk properties, when their orientation distribution function and single crystal properties are known (Mainprice et al., 2011; Mainprice and Humbert, 1994). Thus, the AMS contribution of orthopyroxene, clinopyroxene and the combination of both was modelled in MTex (Hielscher and Schaeben, 2008), based on EBSD data, and averaged augite and enstatite tensors from Biedermann et al. (2015). The modelled orthopyroxene AMS dominates over that of the clinopyroxene. A comparison of measured and modelled AMS directions for selected specimens is shown in Figure 12. The modelled $k^{\prime}$ reaches a maximum of $1.0^{*} 10^{-5}(\mathrm{SI})$; orders of magnitude below the measured $k^{\prime}$ in the respective specimens (Table 2), and a factor of 3 lower than the minimum measured $k^{\prime}$ in the intrusion. Thus, whereas pyroxene clearly possesses an AMS, its contribution to the overall AMS is minor to negligible. As pyroxenes are paramagnetic, they will not contribute to any type of remanence anisotropy, unless they contain exsolutions of ferromagnetic minerals.

The CPO of discrete hemo-ilmenite grains is weak and no consistent relationship between the hemo-ilmenite preferred orientation and AMS has been observed. Therefore, discrete hemo-ilmenite grains are unlikely to add a major contribution to the AMS. Depending on its coercivity, which is defined by the size of lamellae, hemo-ilmenite may add to the ApIRM.

MD magnetite possesses shape anisotropy owing to its internal demagnetizing field, so that AMS reflects grain shape (e.g. Borradaile and Jackson, 2010). Moreover, interaction between neighboring magnetite grains can lead to distribution anisotropy, which has been suggested as a source of AMS in igneous rocks (Hargraves et al., 1991). Thus, magnetite AMS is related to its SPO and arrangement of grains within the rock, i.e. the clustering into mafic bands and aggregates. The two sites with highest $P$-values, BK44 and BK47, possess well-defined layers of dark minerals at the sample scale. Distribution anisotropy of MD magnetite can explain why the minimum susceptibility is observed normal to magmatic layering or foliation. Where present, particularly in layers $d, e$, and $f$, 
magnetite is likely the main carrier of the AMS. Though it is an inefficient carrier of remanence, MD magnetite can contribute to the anhysteretic remanence, and due to its large abundance, it may well constitute the main carrier of AARM.

\subsubsection{Expected AMS and anisotropy of remanence of ferromagnetic exsolutions in pyroxene}

Interestingly, the magnetic fabric appears to be linked to the CPO of orthopyroxene also in specimens whose $k^{\prime}$ exceeds that of pyroxene by several orders of magnitude, and is so large that anisotropy is most likely caused by ferromagnetic minerals. Hemo-ilmenite lamellae with strong preferred orientation can be seen in both pyroxenes, and elongated, commonly oxy-exsolved, magnetite grains in clinopyroxene, by optical microscopy, and a more detailed EBSD map revealed distinct orientation relationships. Thus, pyroxene CPO results in preferred orientation of hemoilmenite and magnetite within the pyroxenes. Hemo-ilmenite exhibits an oblate AMS, with the minimum susceptibility parallel to the (0001) direction (Robinson et al., 2013). The dominant orientation relationship of hemo-ilmenite in orthopyroxene, $(0001) / /(100)$, will cause an AMS carried by hemo-ilmenite with minimum susceptibility parallel to (100) of the orthopyroxene. The minor fraction, (11-20)//(010), will lead to a slightly larger magnetic susceptibility parallel to the orthopyroxene (001) axis, than parallel to its (010) axis, which is consistent with the relationship between CPO and AMS presented in 6.2. The same dominant orientation relationship has been reported by Brown and McEnroe (2004) in the Egersund-Ogna anorthosite. The contribution of hemo-ilmenite exsolutions to the AMS has been modelled for specimen BK2015_4_1b, for which detailed EBSD data was available. Single crystal properties were approximated by tensors as calculated from AMS measurements on hemo-ilmenite ores with planar fabric by Hargraves (1959), and by single crystal data from Robinson et al. (2006), assuming a rotationally oblate shape. This leads to $k^{\prime}$ equal to $6.6^{*} 10^{-4}$, and $4.2 * 10^{-3}$, respectively, approximately an order of magnitude lower than $k^{\prime}$ measured on the same specimen.

Magnetite exsolutions are extended within the (010) plane of clinopyroxene. This is consistent with results shown by Feinberg et al. (2004), who describe magnetite exsolutions either parallel to [100] or [001], together defining the (010) plane of clinopyroxene. Frandsen et al. (2004) describe elongated, blade- and rod-shaped, PSD and MD magnetite exsolutions within clinopyroxene. Due to shape anisotropy, the maximum susceptibility from magnetite exsolutions is expected to lie within the (010) plane, and the minimum normal to (010). Consistent with this, the ferromagnetic contribution to the AMS in clinopyroxene crystals shows a minimum susceptibility normal to the (010) plane, and a maximum between [100] and [001] (Biedermann et al., 2015). Thus, magnetite 
exsolutions in clinopyroxene cannot account for the observed directional correlation between AMS and clinopyroxene CPO, and they are not major contributors to the AMS, nor to the AARM.

\subsubsection{AMS carriers in each layer of the BKS intrusion}

Layers a and c are nominally magnetite-free, however, magnetic data indicate that small amounts of magnetite are present in some of these sites, in agreement with McEnroe et al. (2009a). Only in specimens of Group (3), and BK2015_29 (Group (2)) do the rock magnetic results agree with petrographic studies, and indicate absence of magnetite. These specimens display significant AMS, with $k^{\prime}$ up to $5^{*} 10^{-4}$, but no AARM or ApIRM. Based on these observations, and the AMS directions, orthopyroxene is the most likely candidate to carry the AMS. However, the observed $k^{\prime}$ is higher than previously observed for pyroxene alone, and samples from the a layers do not contain significant amounts of pyroxene. Thus, we suggest that hemo-ilmenite also contributes to the AMS, even though it does not carry a significant ApIRM at $1 \mathrm{~T}$ magnetizing fields.

In Group (2), $k^{\prime}$ varies between $3.9 * 10^{-5}$ to $3.3 * 10^{-2}$, and is on the order of $10^{-4}$ for most specimens. The variation is likely related to the amount of magnetite present. AARM is significant in ca. 2/3 of the specimens, and ApIRM is significant in all measured specimens except one. Depending on whether AARM, ApIRM or both are significant, the AMS is most likely carried by magnetite, hemoilmenite or a combination.

Layers $d-f(G r o u p(1))$ contain large amounts of oxy-exsolved magnetite. The degree of anisotropy varies over several orders of magnitude, and maximum values for $k^{\prime}$ are on the order of $10^{-1}$. All but two specimens of Group (1) display a strong AARM, whereas the ApIRM may or may not be significant. Such high $k^{\prime}$, and the strong AARM approximately coaxial to the AMS, indicates that magnetite is the dominant AMS carrier in these rocks. Magnetite exsolutions in clinopyroxenes cannot account for the observed orientations of AMS and AARM principal axes. Therefore, a SPO and/or distribution anisotropy of discrete MD magnetite grains is the most likely source of anisotropy in these rocks. Certain specimens in this group also possess ApIRM, indicating that hemo-ilmenite contributes to the anisotropy in these specimens.

Preferentially oriented hemo-ilmenite exsolutions have been identified by optical microscopy in specimens from all groups. Thus the lack of an ApIRM fabric, especially in specimens from Group (1), could be explained by a low signal-to noise ratio in the remanence measurements, related to the relative abundances of hemo-ilmenite and magnetite, and/or our inability to fully saturate the hemoilmenite in some of these specimens, owing to a larger coercivity. More work will be needed to determine the contribution of hemo-ilmenite to the AMS. Torque magnetometry has been used to separate AMS components due to paramagnetic minerals, magnetite, and high-coercivity hematite 
(Martín-Hernández and Hirt, 2004) and may be able to resolve the contributions from paramagnetic minerals, magnetite and hemo-ilmenite in the rocks from the BKS intrusion.

To summarize, our data shows that the AMS of certain specimens is dominated by MD magnetite, whereas in others it is carried by a combination of hemo-ilmenite and pyroxene. Thus, similar to e.g. the mafic layered Insizwa sill (Ferré et al., 2002; Maes et al., 2008), the dominant carrier of the AMS varies in accordance with petrographic layering. Also the AMS parameters change with mineralogy, i.e. both $P$ and $k^{\prime}$ are generally lower in a and c-layers than in $d-f$-layers. The orientation of the AMS principal axes, however, appears independent of the mineral carrier, or of whether the AMS is due to SPO and distribution anisotropy (MD magnetite) or magnetocrystalline anisotropy (hemo-ilmenite and pyroxene). A plausible explanation for this behavior is the common deformation experienced by each mineral phase, causing a SPO/distribution anisotropy of discrete magnetite parallel to the pyroxene CPO.

\subsection{Geological implications}

If the magnetic fabric is taken as a proxy for the macroscopic fabric, it confirms the syncline shape of the intrusion as described from structural, gravity and seismic investigations (Bolle et al., 2002; Deemer and Hurich, 1997; Paludan et al., 1994; Smithson and Ramberg, 1979). In particular, the data presented here agree with Paludan et al. (1994)'s observation of an overturned limb in the northeast of the Bjerkreim lobe of the BKS intrusion: the orientation of the minimum susceptibility axes indicates a magnetic foliation dipping outward. Previous studies (Bolle et al., 2000; Paludan et al., 1994) describe foliation-dominated fabrics on the limbs and lineation-dominated fabrics in the hinge zone. In contrast, magnetic fabrics, both AMS and AARM, are mostly prolate throughout the intrusion. Especially, strongly magnetic sites in the E and NE display prolate magnetic fabrics. Magnetic fabrics are most consistent on the limbs of the fold, while some variation is observed in the early MCUs and the hinge zone, which agrees with observations by Paludan et al. (1994), who describe that the magmatic layering and foliation are strongest and parallel to one another on the limbs. In the hinge zone, layering is weaker and foliation is parallel to the axial plane of the fold, at an angle to the layering. It appears that magnetic fabrics may reflect either the layering or foliation depending on the site.

Magnetic fabrics in the cumulate series generally agree with AMS in the acidic rocks as described by Bolle et al. (2000). However, detailed comparison shows that whereas the magnetic lineations of the acidic rocks (maximum susceptibility axes) consistently plunges towards the centre of the intrusion, the lineation of the cumulates differs in the NE and $E$, where it plunges towards the W and $\mathrm{N}$, respectively, parallelling the structural contact of the intrusion (cf. Fig. 11). Thus, the 
present data do not confirm the purely convergent flow pattern as described for the acidic rocks by Bolle et al. (2000), but instead may support the interpretation of Paludan et al. (1994) of additional shear components on the limbs of the syncline, also resulting in the locally overturned limb along the northeastern contact.

\section{Conclusions}

Magnetic fabrics have been measured on 361 specimens from the Bjerkreim lobe of the BKS layered intrusion. Two oxide minerals are identified as magnetic carriers: (1) hemo-ilmenite which occurs in layers a-e, and (2) magnetite, which dominates in layers d, e, and f, and may be present in small amounts in layers a and c. Because the magnetic susceptibility and saturation magnetization of magnetite are far higher than that of hemo-ilmenite, it can contribute a significant amount to the magnetic fabric in these layers. Anisotropy of magnetic susceptibility and remanence have been compared to macroscopic fabrics and CPO data as obtained from EBSD. The magnetic anisotropy appears to correlate with orthopyroxene, and to a lesser extent clinopyroxene, texture, i.e. the minimum susceptibility and anhysteretic remanence correlate with the (100) axes of ortho- and clinopyroxene, and the maximum susceptibility and anhysteretic remanence direction coincide with the orthopyroxene [001] axes. This strongly implies that the bulk-rock anisotropy is somehow due to the pyroxene orientations. However, the $k^{\prime}$ displayed by most specimens is much higher than for single pyroxene crystals, and pyroxene cannot directly carry the anisotropy of remanence. Hemoilmenite exsolutions in orthopyroxene and clinopyroxene have specific orientation relationships to their host, which can explain why the magnetic fabrics best relate to pyroxene CPOs. The magnetite SPO and distribution is likely coaxial to the pyroxene fabric because they underwent the same deformation history. More work will be needed to determine the contribution of hemo-ilmenite to anisotropy. The results presented here can be used for future structural interpretation of the BKS, paleomagnetic studies, and the interpretation of magnetic anomalies over the BKS layered intrusion.

\section{Acknowledgments}

Alexander Michels, Norwegian University of Science and Technology (NTNU), is thanked for assistance during fieldwork. We are grateful to Bjarne S.G. Almqvist, Uppsala University, who provided access to their Kappabridge for initial AMS measurements. Peat Solheid is thanked for technical assistance during sample preparation and measurements at the Institute for Rock Magnetism (IRM), University of Minnesota. This study was financed by the Swiss National Science Foundation, project P2EZP2-155517 to A. Biedermann, NTNU and NFR grant 222666 to S. McEnroe. The first author had a visiting fellowship at the IRM, which is supported by the Instruments and Facilities program of the US National Science Foundation, Division of Earth Sciences. FH was supported through DFG grant He3258/2-1. Eric C. Ferré and Philippe Robion are thanked for their 
careful and thorough reviews, and Philippe Agard for the handling of the manuscript and his additional comments, all of which helped to improve the manuscript.

\section{References}

Aitken, M.J., Alcock, P.A., Bussell, G.D., Shaw, C.J., 1981. Archaeomagnetic determineation of the past geomagnetic intensity using ancient ceramics: allowance for anisotropy. Archaeometry 23, 53-64.

Anson, G.L., Kodama, K.P., 1987. Compaction-induced inclination shallowing of the post-depositional remanent magnetization in a synthetic sediment. Geophysical Journal of the Royal Astronomical Society 88, 673-692.

Archanjo, C.J., Bouchez, J.-L., Corsini, M., Vauchez, A., 1994. The Pombal granite pluton: magnetic fabric, emplacement and relationships with the Brasiliano strike-slip setting of NE Brazil (Paraiba State). Journal of Structural Geology 16, 323-335.

Archanjo, C.J., Bouchez, J.L., 1997. Magnetic fabrics and microstructures of the post-collisional aegirine-augite syenite Triunfo pluton, northeast Brazil. Journal of Structural Geology 19, 849860.

Balsley, J.R., Buddington, A.F., 1960. Magnetic susceptibility anisotropy and fabric of some Adirondack granites and orthogneisses. American Journal of Science 258-A, 6-20.

Bascou, J., Raposo, M.I.B., Vauchez, A., Egydio-Silva, M., 2002. Titanohematite lattice-preferred orientation and magnetic anisotropy in high-temperature mylonites. Earth and Planetary Science Letters 198, 77-92.

Beck Jr., M.E., Lindsley, N.C., 1969. Paleomagnetism of the Beaver Bay Complex, Minnesota. Journal of Geophysical Research 74, 2002-2013.

Biedermann, A.R., Kunze, K., Zappone, A.S., Hirt, A.M., 2015. Origin of magnetic fabric in ultramafic rocks. IOP Conference Series: Materials Science and Engineering 82.

Biedermann, A.R., Pettke, T., Angel, R.J., Hirt, A.M., 2016. Anisotropy of magnetic susceptibility in alkali feldspar and plagioclase. Geophysical Journal International 205, 479-489.

Biedermann, A.R., Pettke, T., Bender Koch, C., Hirt, A.M., 2015. Magnetic anisotropy in clinopyroxene and orthopyroxene single crystals. Journal of Geophysical Research - Solid Earth 120, 14311451.

Boiron, T., Bascou, J., Camps, P., Ferré, E.C., Maurice, C., Guy, B., Gerbe, M.-C., Launeau, P., 2013. Internal structure of basalt flows: Insights from magnetic and crystallographic fabrics of the La Palisse volcanics, French Massif Central. Geophysical Journal International 193, 585-602.

Bolle, O., Diot, H., Duchesne, J.-C., 2000. Magnetic fabric and deformation in charnockitic igneous rocks of the Bjerkreim-Sokndal layered intrusion (Rogaland, Southwest Norway). Journal of Structural Geology 22, 647-667.

Bolle, O., Trindade, R.I.F., Bouchez, J.L., Duchesne, J.C., 2002. Imaging downward granitic magma transport in the Rogaland Igneous Complex, SW Norway. Terra Nova 14, 87-92.

Borradaile, G., 1987. Anisotropy of magnetic susceptibility: rock composition versus strain. Tectonophysics 138, 327-329.

Borradaile, G., Mothersill, J., Tarling, D., Alford, C., 1985/86. Sources of magnetic susceptibility in a slate. Earth and Planetary Science Letters 76, 336-340.

Borradaile, G.J., Henry, B., 1997. Tectonic applications of magnetic susceptibility and its anisotropy. Earth-Science Reviews 42, 49-93.

Borradaile, G.J., Jackson, M., 2010. Structural geology, petrofabrics and magnetic fabrics (AMS, AARM, AIRM). Journal of Structural Geology 32, 1519-1551.

Borradaile, G.J., Lagroix, F., 2000. Thermal enhancement of magnetic fabrics in high grade gneisses. Geophysical Research Letters 27, 2413-2416.

Bressler, S.C., Elston, D.P., 1980. Declination and inclination errors in experimentally deposited specularite-bearing sand. Earth and Planetary Science Letters 48, 227-232. 
Brown, H.C., Khan, M.A., Stacey, F.D., 1964. A search for flow structure in columnar basalt using magnetic anisotropy measurements. Pure and applied geophysics 57, 61-65.

Brown, L.L., McEnroe, S.A., 2004. Palaeomagnetism of the Egersund-Ogna anorthosite, Rogaland, Norway, and the position of Fennoscandia in the Late Proterozoic. Geophysical Journal International 158, 479-488.

Brown, L.L., McEnroe, S.A., 2015. 916 Ma Pole for southwestern Baltica: palaeomagnetism of the Bjerkreim-Sokndal layered intrusion, Rogaland Igneous Complex, southern Norway. Geophysical Journal International 203, 567-587.

Chadima, M., Hansen, A., Hirt, A.M., Hrouda, F., Siemens, H., 2004. Phyllosilicate preferred orientation as a control of magnetic fabric: Evidence from neutron texture goniometry and low and high-field magnetic anisotropy (SE Rhenohercynian Zone of Bohemian Massif), in: MartínHernández, F., Lüneburg, C.M., Aubourg, C., Jackson, M. (Eds.), Magnetic Fabric: Methods and Applications. The Geological Society, London UK, pp. 361-380.

Charlier, B., Namur, O., Latypov, R., Tegner, C., 2015. Layered Intrusions. Springer, Heidelberg, Germany.

Charlier, B., Vander Auwera, J., Duchesne, J.C., 2005. Geochemistry of cumulates from the BjerkreimSokndal layered intrusion (S. Norway): Part II: REE and the trapped liquid fraction. Lithos 83, 255-276.

Clark, D.A., 1997. Magnetic petrophysics and magnetic petrology: aids to geological interpretation of magnetic surveys. Journal of Australian Geology and Geophysics 17, 83-103.

Clark, D.A., 2014. Methods for determining remanent and total magnetizations of magnetic sources a review. Exploration Geophysics 45, 271-304.

Clark, D.A., Schmidt, P.W., 1994. Magnetic properties and magnetic signatures of BIFs of the Hamersley Basin and Yilgarn Block, Western Australia. In: Geophysical Signatures of Western Australian Mineral Deposits, Geology and Geophysics Department (Key Centre) \& UWA Extension, University of Western Australia 26, 343-354.

Cogné, J.-P., Perroud, H., 1985. Strain removal applied to paleomagnetic directions in an orogenic belt: the Permian red slates of the Alpes Maritimes, France. Earth and Planetary Science Letters 72, 125-140.

Cogné, J.P., 1987. TRM deviations in anisotropic assemblages of multidomain magnetite. Geophysical Journal of the Royal Astronomical Society 91, 1013-1023.

Cogné, J.P., 1988. Strain-induced AMS in the granite of Flamanville and its effects upon TRM acquisition. Geophysical Journal 92, 445-453.

Cox, A., Doell, R.R., 1967. Measurement of high-coercivity magnetic anisotropy, in: Collinson, D.W., Creer, K.M., Runcorn, S.K. (Eds.), Methods in Paloemagnetism. Elsevier, pp. 477-482.

Daly, L., Zinsser, H., 1973. Etude comparative des anisotropies de susceptibilité de d'aimantation rémanente isotherme: Conséquences pour l'analyse structural et le paléomagnétisme. Annales de Geophysique 29, 189-200.

Deemer, S., Hurich, C., 1997. Seismic image of the basal portion of the Bjerkreim-Sokndal layered intrusion. Geology 25, 1107-1110.

de Oliveira, D.C., Neves, S.P., Trindade, R.I.F., Dall'Agnol, R., Mariano, G., Correia, P.B., 2010. Magnetic anisotropy of the Redencao granite, eastern Amazonian craton (Brazil): Implications for the emplacement of A-type plutons. Tectonophysics 493, 27-41.

Duchesne, J.C., 1972. Iron-Titanium Oxide Minerals in the Bjerkreim-Sogndal Massif, South-western Norway. Journal of Petrology 13, 57-81.

Duchesne, J.C., 2001. The Rogaland Intrusive Massifs - an excursion guide. NGU Report 2001.029, 139 $\mathrm{pp}$.

Duchesne, J.C., Charlier, B., 2005. Geochemistry of cumulates from the Bjerkreim-Sokndal layered intrusion (S. Norway). Part I: Constraints from major elements on the mechanism of cumulate formation and on the jotunite liquid line of descent. Lithos 83, 229-254.

Dunlop, D.J., Özdemir, O., 1997. Rock Magnetism. Fundamentals and Frontiers. Cambridge University Press, Cambridge, UK. 
Ellwood, B.B., 1978. Flow and emplacement direction determined for selected basaltic bodies using magnetic susceptibility anisotropy measurements. Earth and Planetary Science Letters 41, 254264.

Feinberg, J.M., Wenk, H.-R., Renne, P.R., Scott, G.R., 2004. Epitaxial relationships of clinopyroxenehosted magnetite determined using electron backscatter diffraction (EBSD) technique. American Mineralogist 89, 462-466.

Feinberg, J.M., Wenk, H.-R., Scott, G.R., Renne, P.R., 2006. Preferred orientation and anisotropy of seismic and magnetic properties in gabbronorites from the Bushveld layered intrusion. Tectonophysics 420, 345-356.

Ferré, E.C., Bordarier, C., Marsh, J.S., 2002. Magma flow inferred from AMS fabrics in a layered mafic sill, Insizwa, South Africa. Tectonophysics 354, 1-23.

Ferré, E.C., Maes, S.M., Butak, K.C., 2009. The magnetic stratification of layered mafic intrusions: Natural examples and numerical models. Lithos 111, 83-94.

Ferré, E.C., Martin-Hernandez, F., Teyssier, C., Jackson, M., 2004. Paramagnetic and ferromagnetic AMS in migmatites: Measurements in high and low fields and kinematic implications. Geophysical Journal International 157, 1119-1129.

Ferré, E.C., Michelsen, K.J., Gary Ernst, W., Boyd, J.D., Canon-Tapia, E., 2012. Vertical zonation of the Barcroft granodiorite, White Mountains, California: Implications for magmatic processes. American Mineralogist 97, 1049-1059.

Frandsen, C., Stipp, S.L.S., McEnroe, S.A., Madsen, M.B., Knudsen, J.M., 2004. Magnetic domain structures and stray fields of individual elongated magnetite grains revealed by magnetic force microscopy (MFM). Physics of the Earth and Planetary Interiors 141, 121-129.

Fuller, M.D., 1963. Magnetic anisotropy and paleomagnetism. Journal of Geophysical Research 68, 293-309.

Fuller, M.D., 1960. Anisotropy of susceptibility and the natural remanent magnetization of some Welsh slates. Nature 186, 790-792.

Halvorsen, E., 1974. The magnetic fabric of some dolerite intrusions, Northeast Spitsbergen; implications for their mode of emplacement. Earth and Planetary Science Letters 21, 127-133.

Hargraves, R.B., 1959. Magnetic anisotropy and remanent magnetism in hemo-ilmenite from ore deposits at Allard Lake, Quebec. Journal of Geophysical Research 64, 1565-1578.

Hargraves, R.B., Johnson, D., Chan, C.Y., 1991. Distribution anisotropy: the cause of AMS in igneous rocks? Geophysical Research Letters 18, 2193-2196.

Henry, B., 1983. Interprétation quantitative de l'anisotropie de susceptibilité magnetique. Tectonophysics 91, 165-177.

Henry, B., Daly, L., 1983. From qualitative to quantitative magnetic anisotropy analysis: The prospect of finite strain calibration. Tectonophysics 98, 327-336.

Herrero-Bervera, E., Walker, G.P.L., Cañon-Tabia, E., Garcia, M.O., 2001. Magnetic fabric and inferred flow direction of dikes, conesheets and sill swarms, Isle of Skye, Scotland. Journal of Volcanology and Geothermal Research 106, 195-210.

Hielscher, R., Schaeben, H., 2008. A novel pole figure inversion method: specification of the MTex algorithm. Journal of Applied Crystallography 41, 1024-1037.

Hirt, A.M., Brem, F., Hanzlik, M., Faivre, D., 2006. Anomalous magnetic properties of brain tissue at low temperature: The $50 \mathrm{~K}$ anomaly. Journal of Geophysical Research 111.

Hirt, A.M., Evans, K.F., Engelder, T., 1995. Correlation between magnetic anisotropy and fabric for Devonian shales on the Appalachian Plateau. Tectonophysics 247, 121-132.

Hounslow, M.W., 1985. Magnetic fabric arising from paramagnetic phyllosilicate minerals in mudrocks. Journal of the Geological Society 142, 995-1006.

Hrouda, F., 1982. Magnetic anisotropy of rocks and its application in geology and geophysics. Geophysical Surveys 5, 37-82.

Huang, W., van Hinsbergen, D.J.J., Maffione, M., Orme, D.A., Dupont-Nivet, G., Guilmette, C., Ding, L., Guo, Z., Kapp, P., 2015. Lower Cretaceous Xigaze ophiolites formed in the Gangdese forearc: 
Evidence from paleomagnetism, sediment provenance, and stratigraphy. Earth and Planetary Science Letters 415, 142-153.

Hunt, C.P., Moskowitz, B.M., Banerjee, S.K., 1995. Magnetic properties of rocks and minerals, in: Ahrens, T.J. (Ed.), A Handbook of Physical Constants, vol. 3. American Geophysical Union, Washington, DC, pp. 189-204.

Ishikawa, Y., Akimoto, S., 1958. Magnetic property and crystal chemistry of ilmenite (MeTiO3) and hematite (aFe2O3) system. II. Magnetic property. Journal of the Physical Society of Japan 13, 1298-1310.

Ishikawa, Y., 1962. Magnetic properties of ilmenite-hematite system at low temperature. Journal of the Physical Society of Japan 17, 1835-1843.

Jackson, M., Tauxe, L., 1991. Anisotropy of magnetic susceptibility and remanence: Developments in the characterization of tectonic, sedimentary, and igneous fabric. Reviews of Geophysics 29, 371-376.

Jackson, M.J., 1991. Anisotropy of magnetic remanence: A brief review of mineralogical sources, physical origins, and geological applications, and comparison with susceptibility anisotropy. Pure and Applied Geophysics 136, 1-28.

Jelinek, V., 1977. The statistical theory of measuring anisotropy of magnetic susceptibility of rocks and its application.

Jelinek, V., 1981. Characterization of the magnetic fabric of rocks. Tectonophysics 79, T63-T67.

Jelinek, V., 1984. On a mixed quadratic invariant of the magnetic susceptibility tensor. Journal of Geophysics - Zeitschrift Fur Geophysik 56, 58-60.

Jelinek, V., 1996. Measuring anisotropy of magnetic susceptibility on a slowly spinning specimen basic theory. AGICO Print No. 10.

Kelso, P.R., Tikoff, B., Jackson, M., Sun, W., 2002. A new method for the separation of paramagnetic and ferromagnetic susceptibility anisotropy using low field and high field methods. Geophysical Journal International 151, 345-359.

Khan, M.A., 1962. The anisotropy of magnetic susceptibility of some igneous and metamorphic rocks. Journal of Geophysical Research 67, 2873-2885.

King, R.F., 1955. The remanent magnetism of artificially deposited sediments. Geophysical Supplements to the Monthly Notices of the Royal Astronomical Society 7, 115-134.

Kirker, A.I., McClelland, E., 1997. Deflection of magnetic remancence during progressive cleavage development in the Pembrokeshsire Old Red Sandstone. Geophysical Journal International $130,240-250$.

Kodama, K.P., Dekkers, M.J., 2004. Magnetic anisotropy as an aid to identifying CRM and DRM in red sedimenetary rocks. Studia Geophysica Et Geodaetica 48, 747-766.

Korneliussen, A., McEnroe, S.A., Nilsson, L.P., Schiellerup, H., Gautneb, H., Meyer, G.B., Størseth, L.R., 2000. An overview of titanium deposits in Norway. NGU Bulletin 436, 27-38.

Lagroix, F., Borradaile, G.J., 2000. Magnetic fabric interpretation complicated by inclusions in mafic silicates. Tectonophysics 325, 207-225.

Lovlie, R., Torsvik, T., 1984. Magnetic remanence and fabric properties of laboratory deposited hematite-bearing red sandstone. Geophysical Research Letters 11, 229-232.

Lüneburg, C.M., Lampert, S.A., Lebit, H.D., Hirt, A.M., Casey, M., Lowrie, W., 1999. Magnetic anisotropy, rock fabrics and finite strain in deformed sediments of SW Sardinia (Italy). Tectonophysics 307, 51-74.

Maes, S.M., Ferré, E.C., Tikoff, B., Brown, P.E., Marsh, J.S., 2008. Rock magnetic stratigraphy of a mafic layered sill: A key to the Karoo volcanics plumbing system. Journal of Volcanology and Geothermal Research 172, 75-92.

Maes, S.M., Tikoff, B., Ferré, E.C., Brown, P.E., Miller Jr., J.D., 2007. The Sonju Lake layered intrusion, northeast Minnesota: Internal structure and emplacement history inferred from magnetic fabrics. Precambrian Research 157, 269-288. 
Mainprice, D., Hielscher, R., Schaeben, H., 2011. Calculating anisotropic physical properties from texture data using the MTEX open-source package. Geological Society, London, Special Publications 360, 175-192.

Mainprice, D., Humbert, M., 1994. Methods of calculating petrophysical properties from lattice preferred orientation data. Surveys in Geophysics 15, 575-592.

Martín-Hernández, F., Ferré, E.C., 2007. Separation of paramagnetic and ferrimagnetic anisotropies: A review. Journal of Geophysical Research-Solid Earth 112.

Martín-Hernández, F., Hirt, A.M., 2001. Separation of ferrimagnetic and paramagnetic anisotropies using a high-field torsion magnetometer. Tectonophysics 337, 209-221.

Martín-Hernández, F., Hirt, A.M., 2004. A method for the separation of paramagnetic, ferrimagnetic and haematite magnetic subfabrics using high-field torque magnetometry. Geophysical Journal International 157, 117-127.

Martín-Hernández, F., Lüneburg, C.M., Aubourg, C., Jackson, M., 2004. Magnetic Fabrics: Methods and Applications. The Geological Society, London, UK.

McCabe, C., Jackson, M., Ellwood, B.B., 1985. Magnetic anisotropy in the Trenton Limestone: Results of a new technique, anisotropy of anhysteretic susceptibility. Geophysical Research Letters 12, 333-336.

McCammon, C.A., McEnroe, S.A., Robinson, P., Fabian, K., Burton, B.P., 2009. High efficiency of natural lamellar remanent magnetisation in single grains of ilmeno-hematite calculated using Mössbauer spectroscopy. Earth and Planetary Science Letters 288, 268-278.

McEnroe, S.A., Brown, L.L., Robinson, P., 2004a. Earth analog for Martian magnetic anomalies: remanence properties of hemo-ilmenite norites in the Bjerkreim-Sokndal intrusion, Rogaland, Norway. Journal of Applied Geophysics 56, 195-212.

McEnroe, S.A., Brown, L.L., Robinson, P., 2009a. Remanent and induced magnetic anomalies over a layered intrusion: Effects from crystal fractionation and magma recharge. Tectonophysics 478 , 119-134.

McEnroe, S.A., Fabian, K., Robinson, P., Gaina, C., Brown, L.L., 2009b. Crustal Magnetism, Lamellar Magnetism and Rocks That Remember. Elements 5, 241-246.

McEnroe, S.A., Harrison, R.J., Robinson, P., Langenhorst, F., 2002. Nanoscale haematite-ilmenite lamellae in massive ilmenite rock: an example of 'lamellar magnetism' with implications for planetary magnetic anomalies. Geophysical Journal International 151, 890-912.

McEnroe, S.A., Robinson, P., Panish, P., 1996. Rock-magnetic properties, oxide mineralogy, and mineral chemistry in relation to aeromagnetic interpretation and the search for ilmenite reserves. NGU Report 96.060.

McEnroe, S.A., Robinson, P., Panish, P.T., 2000. Chemical and petrographic characterization of ilmenite and magnetite in oxide-rich cumulates of the Sokndal Region, Rogaland, Norway. NGU Bulletin 436, 49-56.

McEnroe, S.A., Robinson, P., Panish, P.T., 2001. Aeromagnetic anomalies, magnetic petrology, and rock magnetism of hemo-ilmenite- and magnetite-rich cumulate rocks from the Sokndal Region, South Rogaland, Norway. American Mineralogist 86, 1447-1468.

McEnroe, S.A., Skilbrei, J.R., Robinson, P., Heidelbach, F., Langenhorst, F., Brown, L.L., 2004b. Magnetic anomalies, layered intrusions and Mars. Geophysical Research Letters 31.

Michot, P., 1960a. La géologie de la catazone: le problème des anorthosites, la palingenèse basique et la tectonique catazonale dans le Rogaland méridional (Norvège méridionale). NGU Bulletin 212, 1-54.

Michot, P., 1960b. Le probleme des intrusions marginales. Geologische Rundschau 50, 94-105.

Michot, P., 1965. Le magma plagioclasique. Geologische Rundschau 54, 956-976.

Moskowitz, B.M., Jackson, M., Kissel, C., 1998. Low-temperature magnetic behavior of titanomagnetites. Earth and Planetary Science Letters 157, 141-149.

Muxworthy, A.R., 1999. Low-temperature susceptibility and hysteresis of magnetite. Earth and Planetary Science Letters 169, 51-58. 
Muxworthy, A.R., McClelland, E., 2000. Review of the low-temperature magnetic properties of magnetite from a rock magnetic perspective. Geophysical Journal International 140, 101-114.

O'Driscoll, B., Ferré, E.C., Stevenson, C.T.E., Magee, C., 2015. The Significance of Magnetic Fabric in Layered Mafic-Ultramafic Intrusions, in: Charlier, B.e.a. (Ed.), Layered Intrusions. Springer Geology.

Paludan, J., Hansen, U.B., Olesen, N.Ø., 1994. Structural evolution of the Precambrian BjerkreimSokndal intrusion, South Norway. Norsk Geologisk Tidsskrift 74, 185-198.

Pares, J.M., van der Pluijm, B.A., 2002. Phyllosilicate fabric characterization by Low-Temperature Anisotropy of Magnetic Susceptibility (LT-AMS). Geophysical Research Letters 29.

Potter, D.K., 2004. A comparison of anisotropy of magnetic remanence methods - a user's guide for application to paleomagnetism and magnetic fabric studies, in: Martín-Hernández, F., Lüneburg, C.M., Aubourg, C., Jackson, M. (Eds.), Magnetic Fabrics: Methods and Applications. The Geological Society, London, UK, pp. 21-35.

Prior, D.J., Boyle, A.P., Brenker, F., Cheadle, M.C., Day, A., Lopez, G., Peruzzo, L., Potts, G.J., Reddy, S., Spiess, R., Timms, N.E., Trimby, P., Wheeler, J., Zetterström, L., 1999. The application of electron backscatter diffraction and orientation contrast imaging in the SEM to textural problems in rocks. American Mineralogist 84, 1741-1759.

Puranen, R., 1989. Susceptibilities, iron and magnetite content of Precambrian rocks in Finland. Geological Survey of Finland, Report of investigation, $54 \mathrm{pp}$.

Robinson, P., Fabian, K., McEnroe, S.A., Heidelbach, F., 2013. Influence of lattice-preferred orientation with respect to magnetizing field on intensity of remanent magnetization in polycrystalline hemo-ilmenite. Geophysical Journal International 192, 514-536.

Robinson, P., Harrison, R.J., McEnroe, S.A., Hargraves, R.B., 2002. Lamellar magnetism in the haematite-ilmenite series as an explanation for strong remanent magnetization. Nature 418, 517-520.

Robinson, P., Harrison, R.J., McEnroe, S.A., Hargraves, R.B., 2004. Nature and origin of lamellar magnetism in the hematite-ilmenite series. American Mineralogist 89, 725-747.

Robinson, P., Heidelbach, F., Hirt, A.M., McEnroe, S.A., Brown, L.L., 2006. Crystallographic-magnetic correlations in single-crystal haemo-ilmenite: new evidence for lamellar magnetism. Geophysical Journal International 165, 17-31.

Robinson, P., Panish, P.T., McEnroe, S.A., 2001. Minor element chemistry of hemo-ilmenite and magnetite in cumulate rocks from the Sokndal Region, South Rogaland, Norway. American Mineralogist 86, 1469-1476.

Rochette, P., 1987. Magnetic susceptibility of the rock matrix related to magnetic fabric studies. Journal of Structural Geology 9, 1015-1020.

Rochette, P., Fillion, G., 1988. Identification of multicomponent anisotropies in rocks using various field and temperature values in a cryogenic magnetometer. Physics of the Earth and Planetary Interiors 51, 379-386.

Rochette, P., Fillion, G., Mollard, P., Vergne, R., 1983. Rock magnetism - analysis of the magnetic anisotropy in rocks using a cryogenic magnetometer. Comptes Rendus De L Academie Des Sciences Serie li 296, 557-559.

Rochette, P., Jackson, M., Aubourg, C., 1992. Rock magnetism and the interpretation of anisotropy of magnetic susceptibility. Reviews of Geophysics 30, 209-226.

Rochette, P., Vialon, P., 1984. Development of planar and linear fabrics in Dauphinois shales and slates (French Alps) studied by magnetic anisotropy and its mineralogical control. Journal of Structural Geology 6, 33-38.

Rogers, J., Fox, J.M.W., Aitken, M.J., 1979. Magnetic anisotropy in ancient pottery. Nature 277, 644646.

Rønning, S., 1995. Helikoptermålinger over kartblad 1311-IV Sokndal. NGU Report 95.120, 14 pp.

Schmidt, V., Hirt, A.M., Rosselli, P., Martín-Hernández, F., 2007. Separation of diamagnetic and paramagnetic anisotropy by high-field, low-temperature torque measurements. Geophysical Journal International 168, 40-47. 
Selkin, P.A., Gee, J.S., Tauxe, L., Meurer, W.P., Newell, A.J., 2000a. The effect of remanence anisotropy on paleointensity estimates: a case study from the Archean Stillwater Complex. Earth and Planetary Science Letters 183, 403-416.

Selkin, P.A., Gee, J.S., Tauxe, L., Meurer, W.P., Newell, A.J., 2000b. The effect of remanence anistoropy on paleointensity estimates: a case study from the Archean Stillwater Complex. Earth and Planetary Science Letters 183, 403-416.

Seront, B., Mainprice, D., Christensen, N.I., 1993. A determination of the three-dimensional seismic properties of anorthosite: Comparison between values calculated from the petrofabric and direct laboratory measurements. Journal of Geophysical Research 98, 2209-2221.

Siegesmund, S., Ullemeyer, K., Dahms, M., 1995. Control of magnetic rock fabrics by mica preferred orientation - a quantitative approach. Journal of Structural Geology 17, 1601-1613.

Smithson, S.B., Ramberg, I.B., 1979. Gravity interpretation of the Egersund anorthosite complex, Norway: Its petrological and geothermal significance. Geological Society of America Bulletin, Part 1 90, 199-204.

Stacey, F.D., 1960. Magnetic anisotropy of igneous rocks. Journal of Geophysical Research 65, 24292442.

Stacey, F.D., Banerjee, S.K., 1974. The Physical Principles of Rock Magnetism. Elsevier.

Stephenson, A., Sadikun, S., Potter, D.K., 1986. A theoretical and experimental comparison of the anisotropies of magnetic susceptibility and remanence in rocks and minerals. Geophysical Journal of the Royal Astronomical Society 84, 185-200.

Stickler, J.J., Kern, S., Wold, A., Heller, G.S., 1967. Magnetic resonance and susceptibility of several ilmenite powders. Physical Review 164, 765-767.

Tan, X., Kodama, K., 2002. Magnetic anisotropy and paleomagnetic inclination shallowing in red beds: evidence from the Mississippian Mauch Chunk Formation, Pennsylvania. Journal of Geophysical Research - Solid Earth 107, EPM9-1 - EPM9-17.

Tarduno, J.A., 1990. Absolute inclination values from deep sea sediments: a reexamination of the Cretaceous Pacific record. Geophysical Research Letters 17, 101-104.

Tarling, D.H., Hrouda, F., 1993. The magnetic anisotropy of rocks. Chapman and Hall, London, UK.

Tauxe, L., Kent, D.V., 1984. Properties of a detrital remanence carried by hematite from study of modern river deposits and laboratory redeposition experiments. Geophysical Journal of the Royal Astronomical Society 77, 543-561.

Thompson, R., Oldfield, F., 1986. Environmental Magnetism. Allen \& Unwin Ltd, London, UK.

Uyeda, S., Fuller, M.D., Belshe, C., Girdler, R.W., 1963. Anisotropy of magnetic susceptibility of rocks and minerals. Journal of Geophysical Research 68, 279-291.

Verwey, E.J.W., 1939. Electronic conduction of magnetite (Fe304) and its transition point at low temperatures. Nature 144, 327-328.

Wilson, J.R., Robins, B., Nielsen, F.M., Duchesne, J.C., Vander Auwera, J., 1996. The BjerkreimSokndal layered intrusion, Southwest Norway, in: Cawthorn, R.G. (Ed.), Layered Intrusions. Elsevier, Amsterdam, pp. 231-255.

Wing-Fatt, L., Stacey, F.D., 1966. Magnetic anisotropy of laboratory materials in which magma flow is simulated. Pure and Applied Geophysics 64, 78-80. 


\section{Table Captions}

Table 1: Sample list, summarizing stratigraphic unit and AF demagnetization groups. * indicates samples from Brown and McEnroe (2015)

Table 2: Comparison of modelled and measured mean deviatoric susceptibility $\left(k^{\prime}\right)$ for specimens on which EBSD data was available. Modelled $k^{\prime}$ is given for orthopyroxene (Opx), clinopyroxene (Cpx), a combination of both pyroxenes, and hemo-ilmenite. Two different single crystal tensors have been used for the latter. 


\begin{tabular}{|c|c|c|c|}
\hline Site & Number of specimens & Layer & AF demagnetization group \\
\hline BK2015_2 & & $8 \mathrm{MCU} \mathrm{IVe}^{\prime}$ & 1 \\
\hline BK2015_4 & & $8 \mathrm{MCU}$ IVe' & 1 \\
\hline BK2015_5 & & 6 MCU IVe' & 1 \\
\hline BK2015_7 & 16 & 6 MCU IVe' & 1 \\
\hline BK2015_9 & 17 & 7 MCU IVe' & 1 \\
\hline BK2015_13 & 16 & 6 MCU IVe' & 1 \\
\hline BK2015_14 & 12 & $2 \mathrm{MCU}$ IVe' & 1 \\
\hline BK2015_16 & & 5 MCU IVe' & 1 \\
\hline BK2015_17 & & 6 MCU IVe' & 1 \\
\hline BK2015_18 & & 8 MCU IVe' & 1 \\
\hline BK2015_20 & & 7 MCU IVe' & 1 \\
\hline BK2015_21 & & 8 MCU IVe' & 1 \\
\hline BK2015_24 & 10 & $0 \mathrm{MCU}$ IVc & 1 \\
\hline BK2015_25 & & $6 \mathrm{MCU}$ IIIf & 1 \\
\hline BK2015_26 & & 8 MCU IVb, MCU IVc & 1 \\
\hline BK2015_27 & & $9 \mathrm{MCU}$ Ivc & 2 \\
\hline BK2015_28 & & $8 \mathrm{MCU}$ IVe & 1 \\
\hline BK2015_29 & & $7 \mathrm{MCU}$ IVc & 2 \\
\hline BK2015_30 & & $6 \mathrm{MCU}$ IVc, MCU IVd & 1 \\
\hline BK2015_31 & & $8 \mathrm{MCU} I V \mathrm{c}$ & 2 \\
\hline BK2015_32 & 11 & $1 \mathrm{MCU}$ IVe' & 1 \\
\hline BK2015_38 & & 7 MCU IVe (f?) & 1 \\
\hline BK2015_39 & & 8 anorthosite & 2 \\
\hline BK2015_40 & & $9 \mathrm{MCU}$ IIIC & 2 \\
\hline BK2015_41 & & $6 \mathrm{MCU}$ IIId & 1 \\
\hline BK2015_42 & & $6 \mathrm{MCU}$ IVb & 1 \\
\hline BK2015_43 & & 5 MCU IVd (MCU IVc) & 1 \\
\hline BK2015_44 & & 7 MCU IVe (f?) & 1 \\
\hline BK2015_45 & & 6 MCU IVe (f?) & 1 \\
\hline BK2015_46 & & 3 MCU IVe (f?) & 1 \\
\hline BK2015_47 & & 5 MCU IVe & 1 \\
\hline BK2015_53 & & 6 altered & 1 \\
\hline BK1 & $*$ & $2 \mathrm{MCU}$ IVf & \\
\hline BK2 & $*$ & $1 \mathrm{MCU} I \mathrm{Vf}$ & \\
\hline BK3 & $*$ & $3 \mathrm{MCU} I \mathrm{Ve}$ & \\
\hline BK5 & $*$ & $3 \mathrm{MCU} \mathrm{IBC}$ & \\
\hline BK7 & $*$ & $2 \mathrm{MCU} \mathrm{IBC}$ & \\
\hline BK8 & $*$ & $2 \mathrm{MCU}$ Ilc & \\
\hline BK10 & $*$ & $2 \mathrm{MCU}$ IAa & \\
\hline BK11 & $*$ & $3 \mathrm{MCU}$ IAa & \\
\hline BK12 & $*$ & $2 \mathrm{MCU}$ IBa & \\
\hline BK31 & $*$ & $2 \mathrm{MCU} I \mathrm{Va}$ & 3 \\
\hline BK32 & $*$ & $3 \mathrm{MCU}$ IIIa & \\
\hline BK34 & $*$ & 6 MCU IVe' & 1 \\
\hline BK38 & $*$ & 7 MCU IVe' & \\
\hline BK44 & $*$ & $3 \mathrm{MCU}$ IIId & \\
\hline BK45 & $*$ & $2 \mathrm{MCU} \| \mathrm{lc}$ & 2 \\
\hline BK46 & $*$ & $3 \mathrm{MCU}$ IVd & \\
\hline BK47 & $*$ & $3 \mathrm{MCU}$ IIId & \\
\hline BK48 & $*$ & $2 \mathrm{MCU}$ IIIa & \\
\hline BK73 & $*$ & 3 quartz mangerite & \\
\hline BK75 & $*$ & $4 \mathrm{MCU}$ IIIC & 2 \\
\hline BK77 & $*$ & $1 \mathrm{MCU}$ IVf & \\
\hline BK86 & $*$ & $2 \mathrm{MCU} I \mathrm{IVb}$ & \\
\hline BK91 & $*$ & $1 \mathrm{MCU}$ IIIC & 2 \\
\hline BK94 & $*$ & 3 mangerite & \\
\hline BK102 & $*$ & $2 \mathrm{MCU} I \mathrm{AC}$ & 1 \\
\hline BK103 & $*$ & $7 \mathrm{MCU}$ IVc & 2 \\
\hline BK104 & 12 & 2 MCU IVe' & \\
\hline BK106 & $*$ & 8 MCU IIla & 1 \\
\hline BK110 & $*$ & $3 \mathrm{MCU}$ IAa & 3 \\
\hline BK111 & $*$ & $6 \mathrm{MCU}$ IBa & 3 \\
\hline
\end{tabular}




\begin{tabular}{lcccccr} 
Sample & \multicolumn{3}{c}{ Modelled k' } & & & Measured I \\
& Opx & Cpx & Opx+Cpx & Hem-Ilm (F Hem-IIm (t & \\
\hline BK2015_4_1b & $6.38 \mathrm{E}-06$ & $3.55 \mathrm{E}-06$ & $3.42 \mathrm{E}-06$ & $4.18 \mathrm{E}-03$ & $6.60 \mathrm{E}-04$ & $2.50 \mathrm{E}-02$ \\
BK2015_7_4b & $8.48 \mathrm{E}-06$ & $4.60 \mathrm{E}-06$ & $7.76 \mathrm{E}-06-$ & - & $2.06 \mathrm{E}-02$ \\
BK2015_14_2c & $8.61 \mathrm{E}-06$ & $4.50 \mathrm{E}-06$ & $4.74 \mathrm{E}-06-$ & - & $1.32 \mathrm{E}-02$ \\
BK2015_17_1b & $1.34 \mathrm{E}-05$ & $4.62 \mathrm{E}-06$ & $9.97 \mathrm{E}-06-$ & - & $3.66 \mathrm{E}-02$ \\
BK2015_18_1a & $7.40 \mathrm{E}-06$ & $4.05 \mathrm{E}-06$ & $6.58 \mathrm{E}-06-$ & - & $1.41 \mathrm{E}-02$ \\
BK2015_21_1C & $6.89 \mathrm{E}-06$ & $5.15 \mathrm{E}-06$ & $4.47 \mathrm{E}-06-$ & - & $1.21 \mathrm{E}-02$ \\
BK2015_26_1b & $1.22 \mathrm{E}-05$ & $1.07 \mathrm{E}-05$ & $9.46 \mathrm{E}-06-$ & - & $3.47 \mathrm{E}-03$ \\
BK2015_30_1a & $7.16 \mathrm{E}-06$ & $1.05 \mathrm{E}-06$ & $6.85 \mathrm{E}-06-$ & - & $7.85 \mathrm{E}-03$
\end{tabular}




\section{Figure 1}

(a)

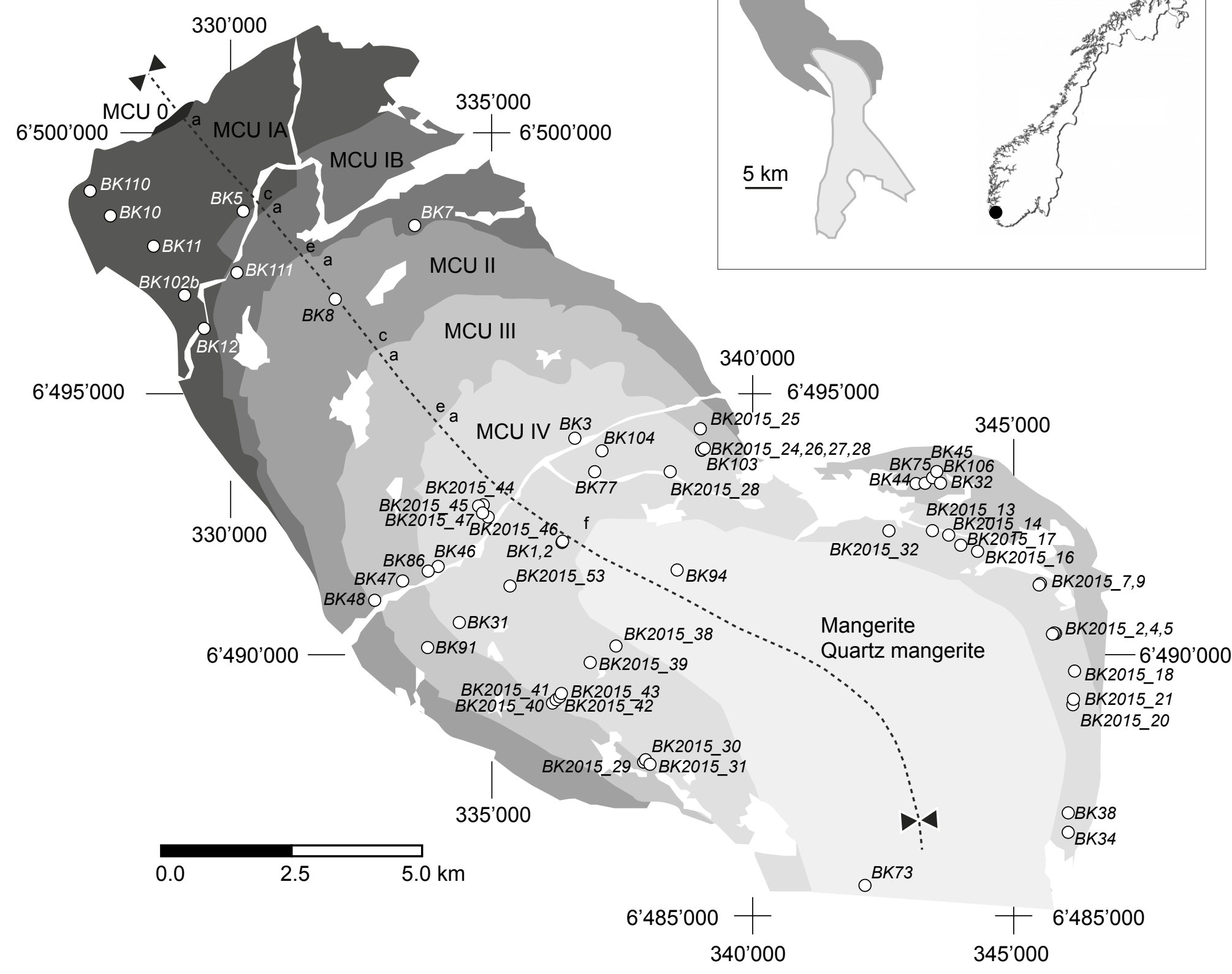

(b)

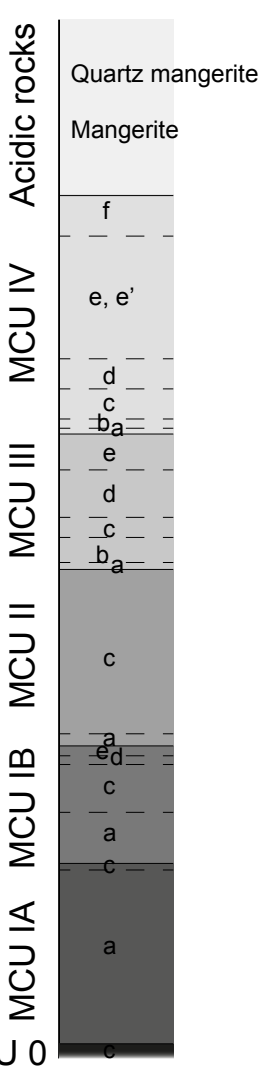

Mineralogy:

a - plg, hem-ilm

b - plg, ol, hem-ilm, mag

c - plg, opx, hem-ilm

d - plg, opx, hem-ilm, mag

e - plg, opx, cpx, ap, hem-ilm, mag

$f$ - plg, pig, Ca-rich px, ap, ilm, mag

ap apatite, cpx clinopyroxene,

hem-ilm hemo-ilmenite, ilm ilmenite, mag magnetite, ol olivine,

opx orthopyroxene, plg plagioclase pig inverted pigeonite

Figure 1: (a) Simplified map of the Bjerkreim lobe of the BKS with sitelocations, redrawn after McEnrot et al. (2009); coordinate system UTM32N in this and subsequent figures. Dashed line indicates fold axis of the syncline, redrawn from Paludan et al. (1994). Small letters next to the fold axis indicate the layers at the bottom and top of each MCU. Inset map shows the relationship of the Bjerkreim lobe (dark grey) to the other parts of the BKS (light grey), redrawn after Wilson et al. (1996), and the study location in southern Norway.(b) Simplified layer stratigraphy and mineralogy, after Wilson et al. (1996). 


\section{Figure 2, black\&white for print}
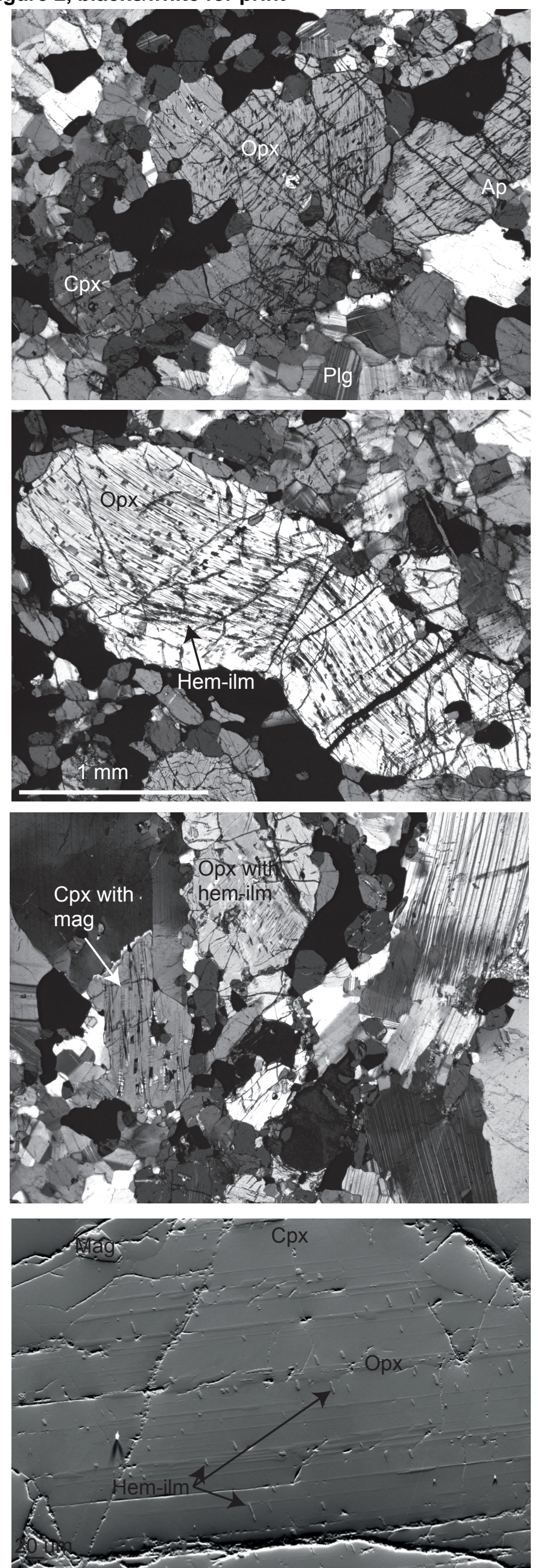

Figure 2: Characteristic thin sections of sites BK2015_16, BK2015_9, BK2015_18 (from top), in crosspolarized light, showing the deformation in orthopyroxene as well as exsolutions within pyroxenes, and SEM image showing exsolutions in a clinopyroxene (bottom). Opx - orthopyroxene, Cpxclinopyroxene, Plg-plagioclase, Ap-apatite, Hem-ilm - hemo-ilmenite, Mag - magnetite. Opaque grains are either magnetite or hemo-ilmenite. 


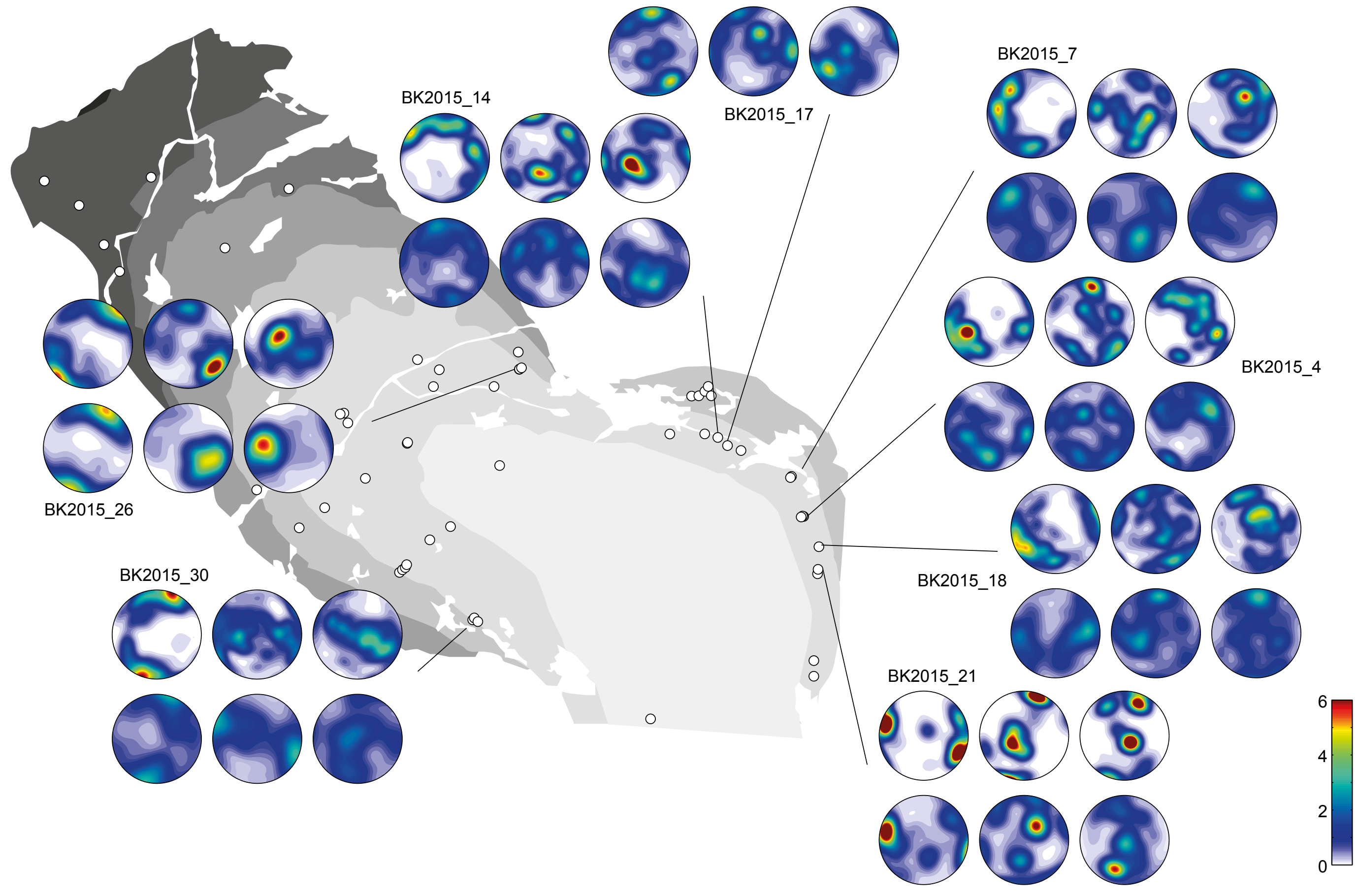

Figure 3: Typical pyroxene textures in different areas of the intrusion. Lower hemisphere stereoplots showing the orientation density functions of (100), (010) and (001) of orthopyroxene, respectively (top row), and (100), (010) and [001] of clinopyroxene (bottom row), in a geographic coordinate system. Stereonets are oriented such that $N$ is at the top of the page, in accordance with the map, in this and subsequent figures. (hkl) indicates the orientation of the normal to crystallographic planes, and [uvw] describes crystallographic axes. Colorscale indicates multiples of random distribution. 


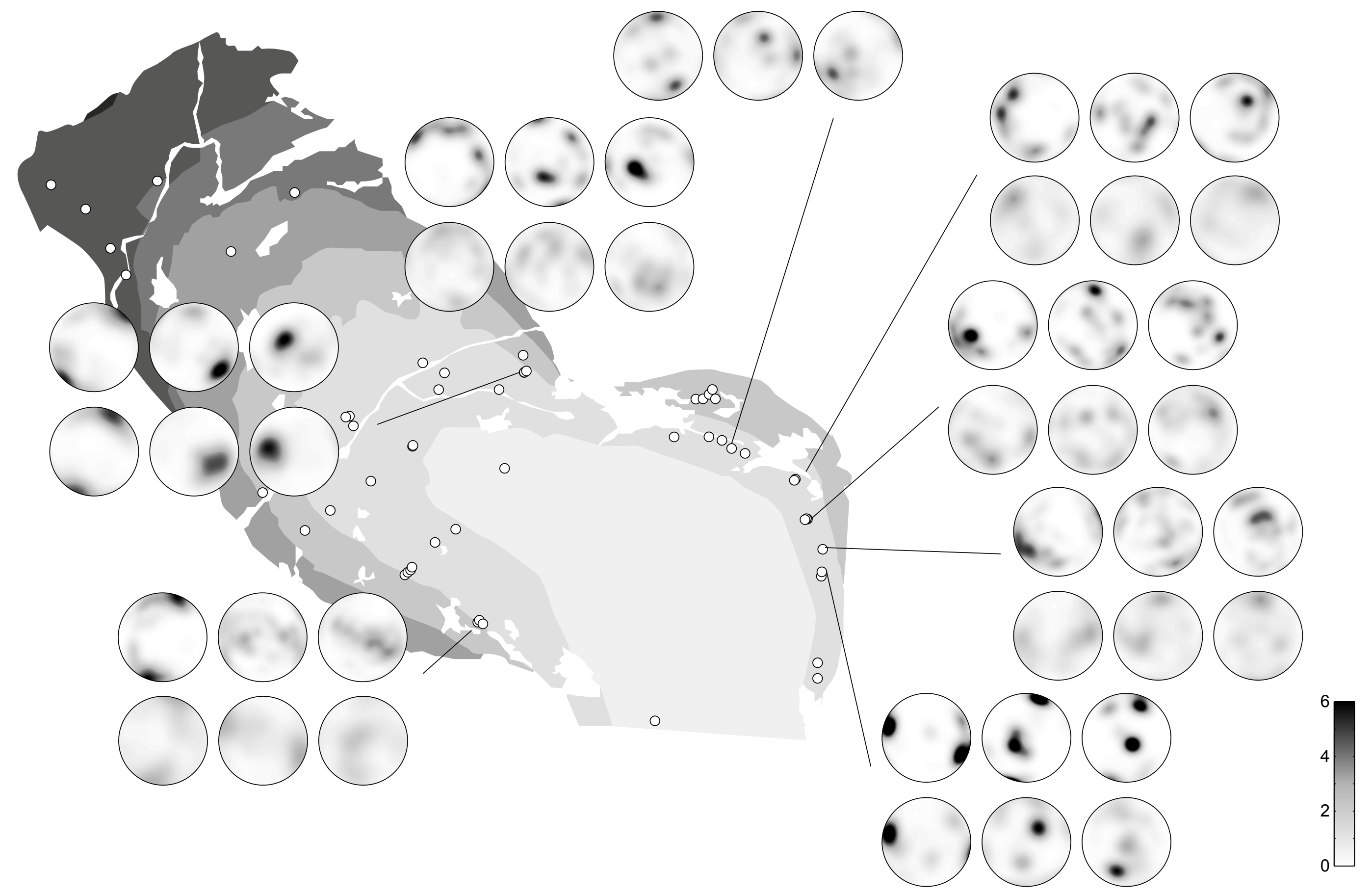

Figure 3: Typical pyroxene textures in different areas of the intrusion. Lower hemisphere stereoplots showing the orientation density functions of (100), (010) and (001) of orthopyroxene, respectively (top row), and (100), (010) and [001] of clinopyroxene (bottom row), in a geographic coordinate system. Stereonets are oriented such that $N$ is at the top of the page, in accordance with the map, in this and subsequent figures. ( $h \mathrm{kl}$ ) indicates the orientation of the normal to crystallographic planes, and [uvw] describes crystallographic axes. Colorscale indicates multiples of random distribution. 
Figure 4

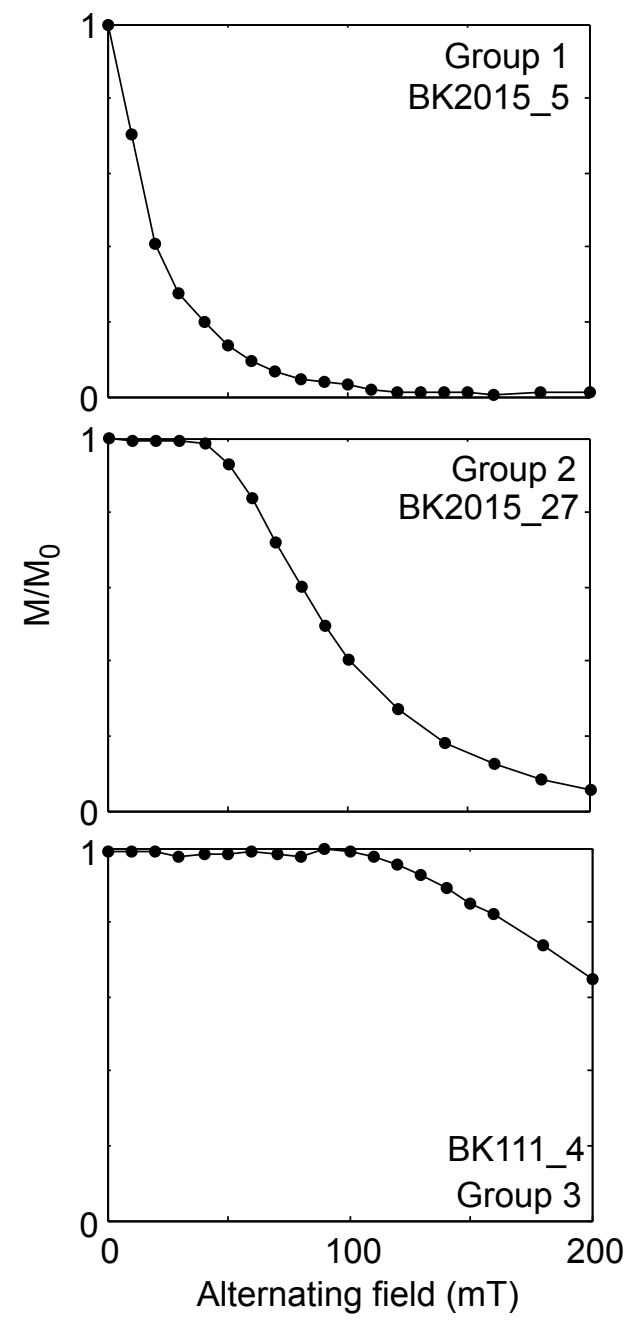

Figure 4: Characteristic AF demagnetization patterns. 
Figure 5

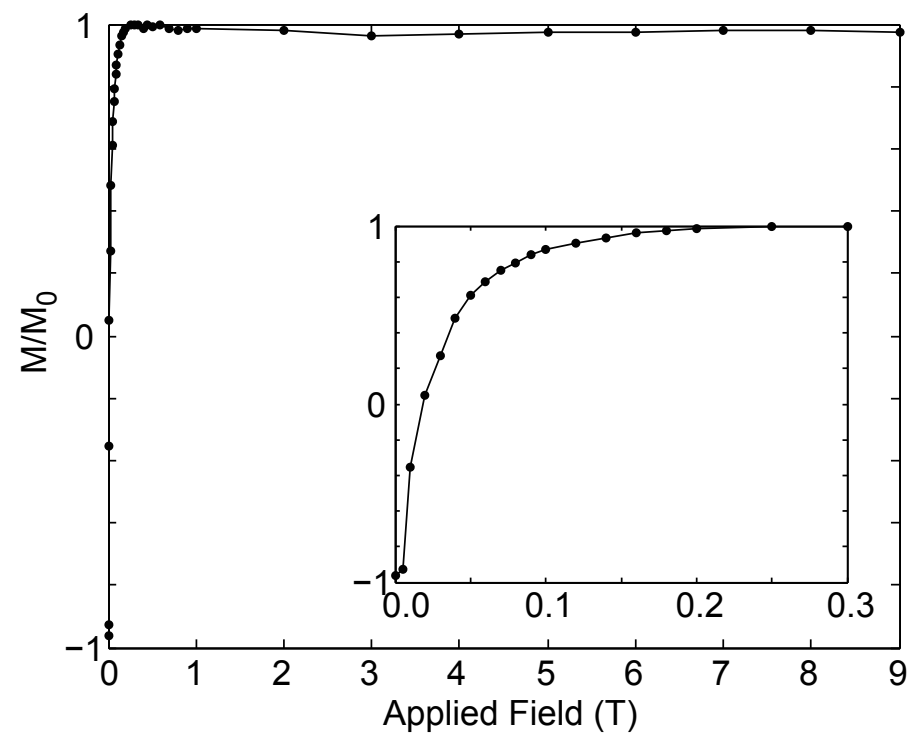

Figure 5: IRM acquisition of specimen BK2015_5_2b. Inset shows the IRM acquisition at low fields. 
Figure 6 , color for online
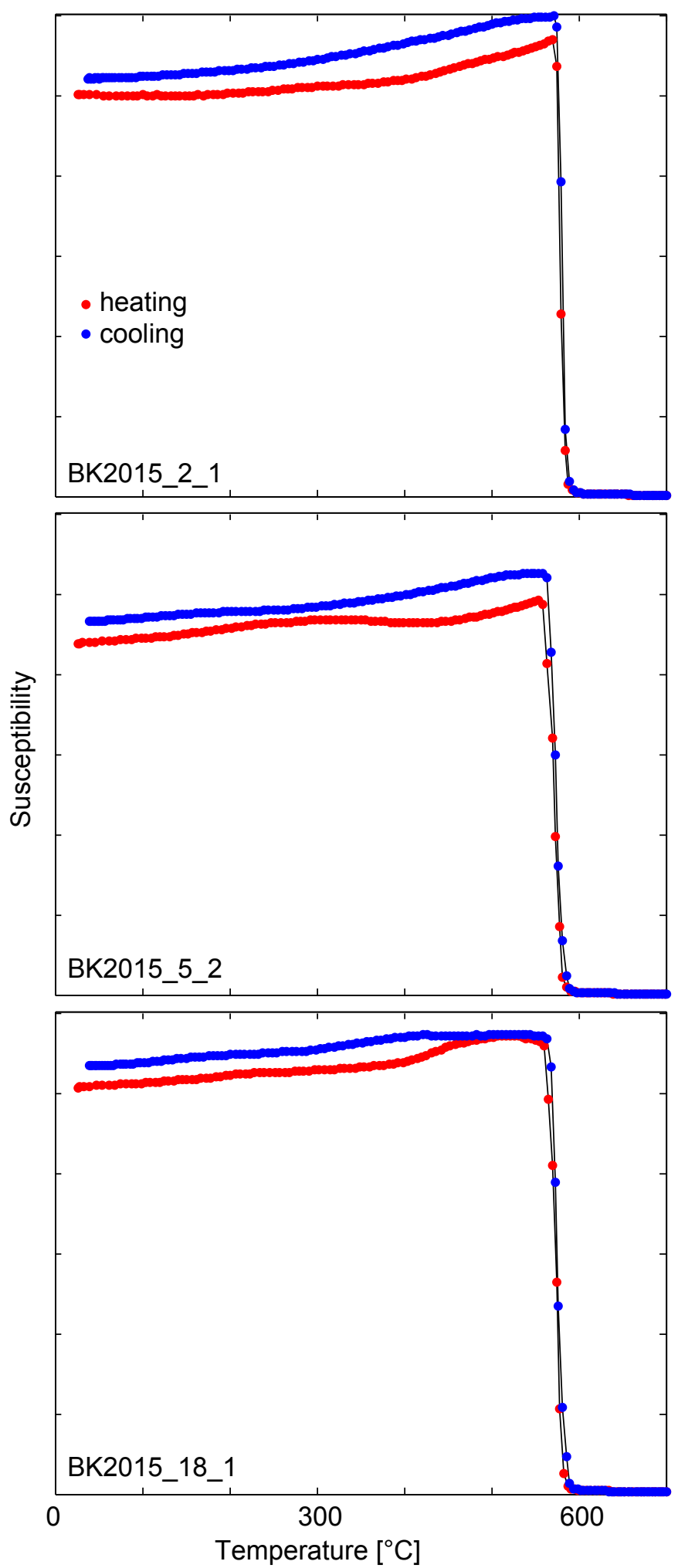

Figure 6: Behavior of magnetic susceptibility during heating and cooling. 
Figure 6, bw for print

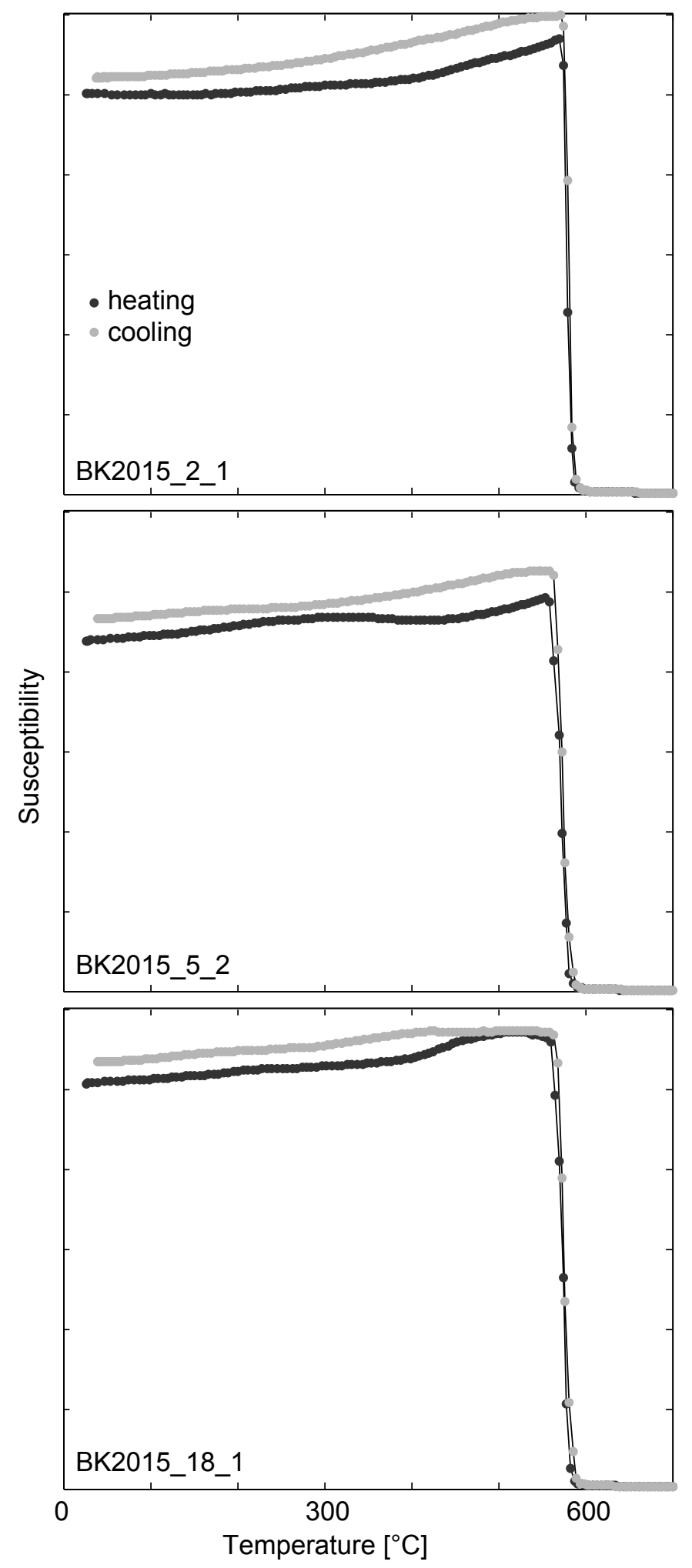

Figure 6: Behavior of magnetic susceptibility during heating and cooling. 

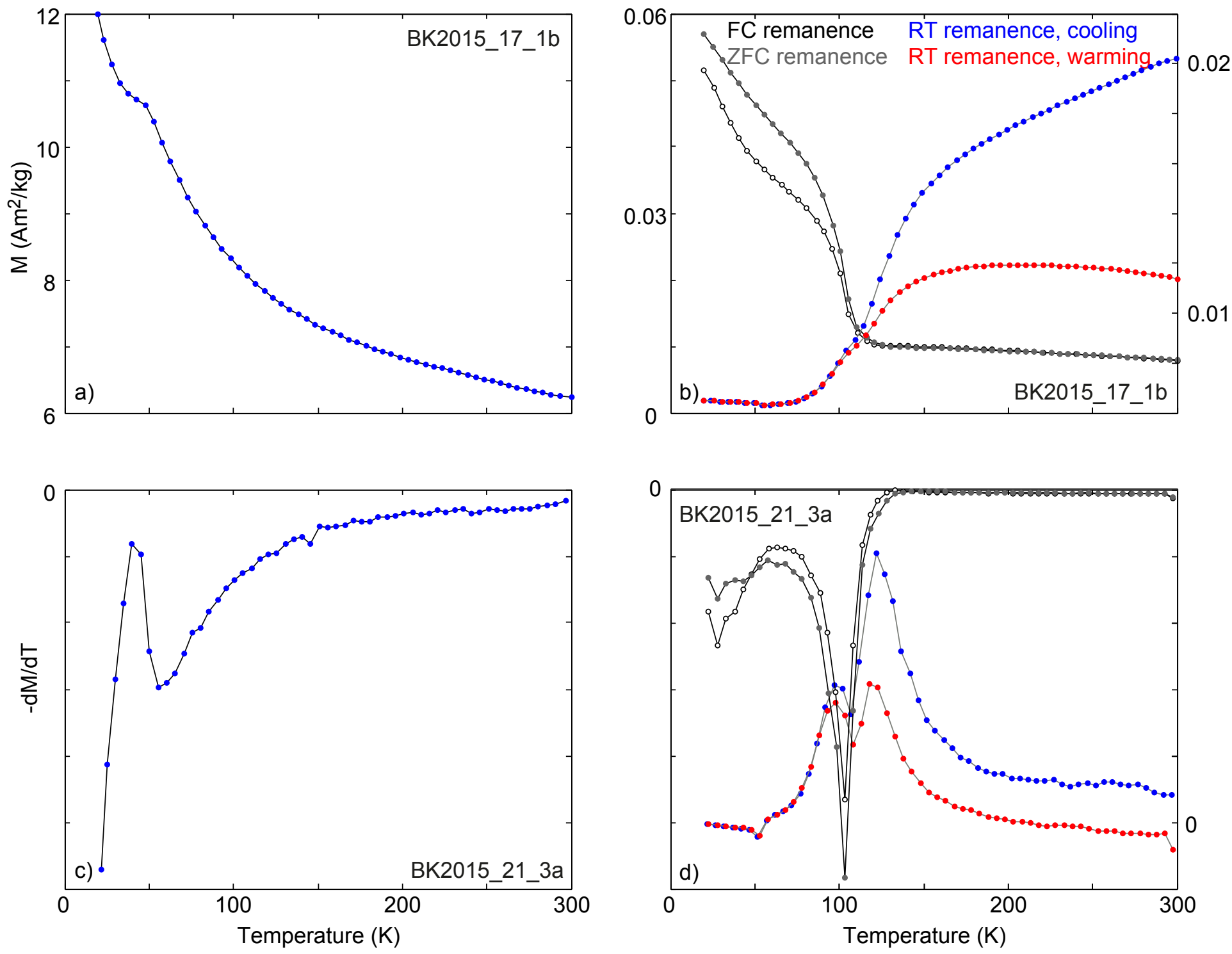

Figure 7: Transitions observed from MPMS data: strong-field magnetization (a), FC remanence and ZFC remanence, and RT remanence during cooling and warming (b). Note different scales for FC/ZFC remanence (left) and $R T$ remanence (right). Derivatives with respect to temperature are shown in (c), (d). 

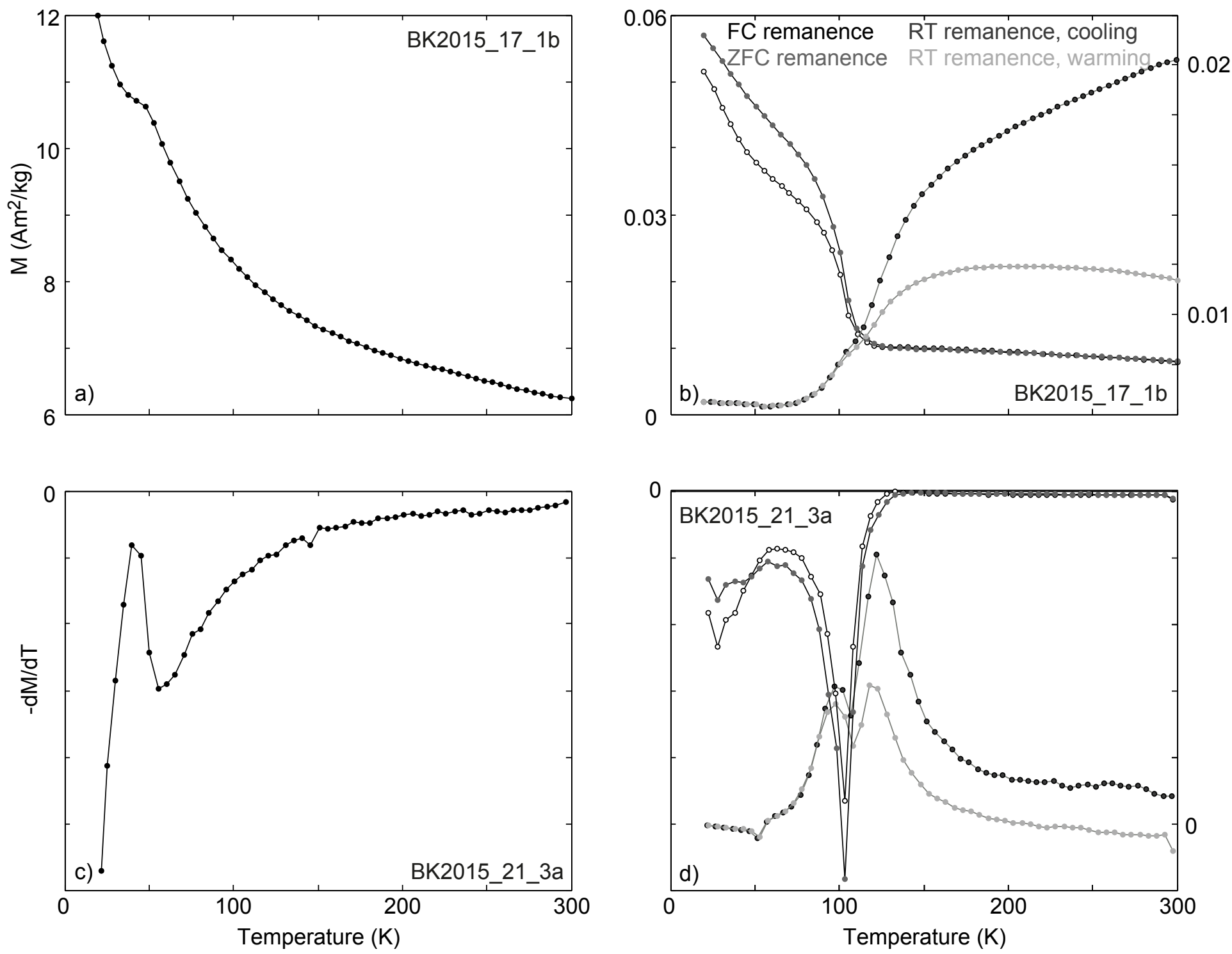

Figure 7: Transitions observed from MPMS data: strong-field magnetization (a), FC remanence and ZFC remanence, and RT remanence during cooling and warming (b). Note different scales for FC/ZFC remanence (left) and RT remanence (right). Derivatives with respect to temperature are shown in (c), (d). 


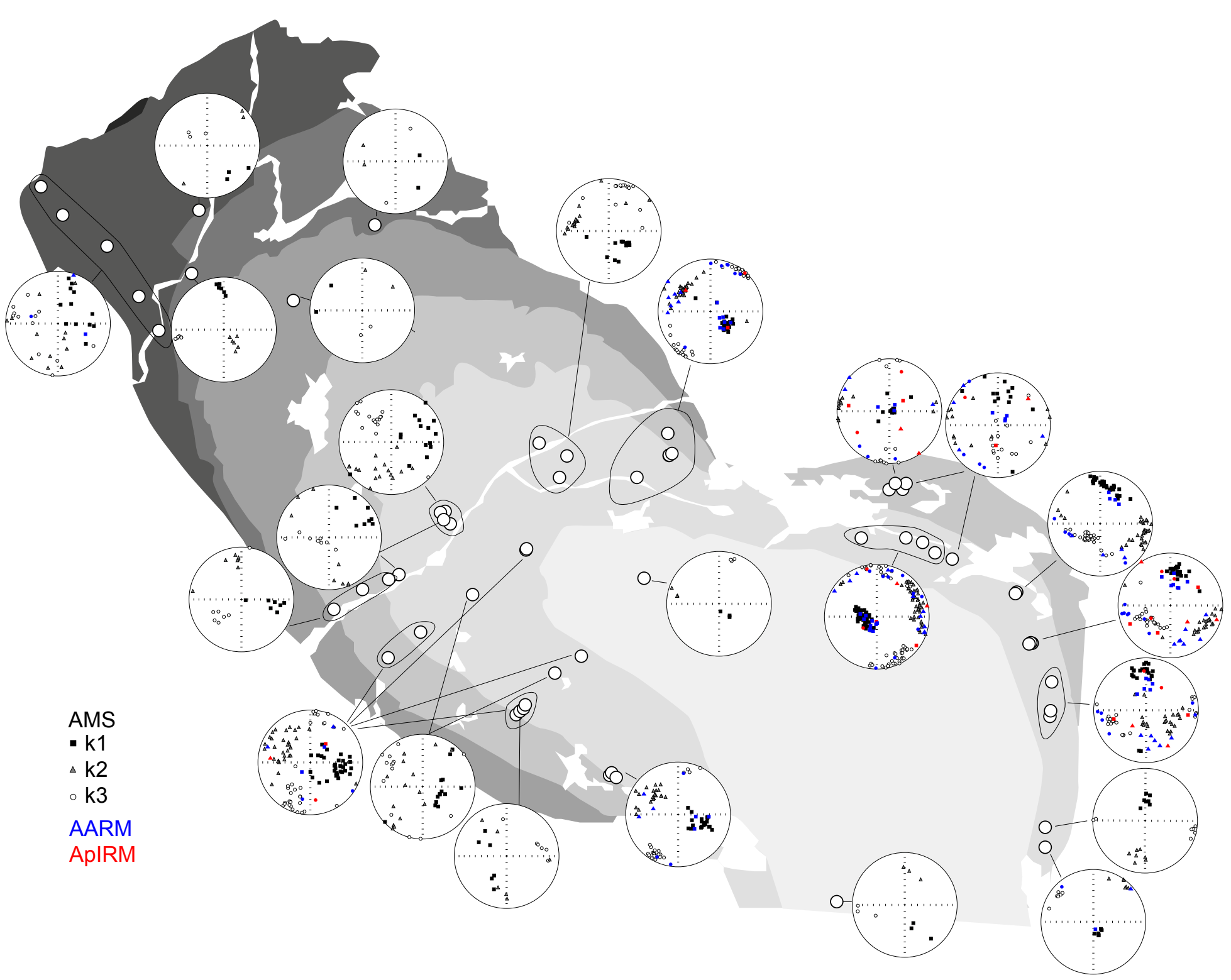

Figure 8: Lower hemisphere equal-area stereoplots showing the directions of principal AMS and anisotropy of remanence axes. cf Figure B, Supplementary Material, for a complete map with separate stereoplots for each site. 


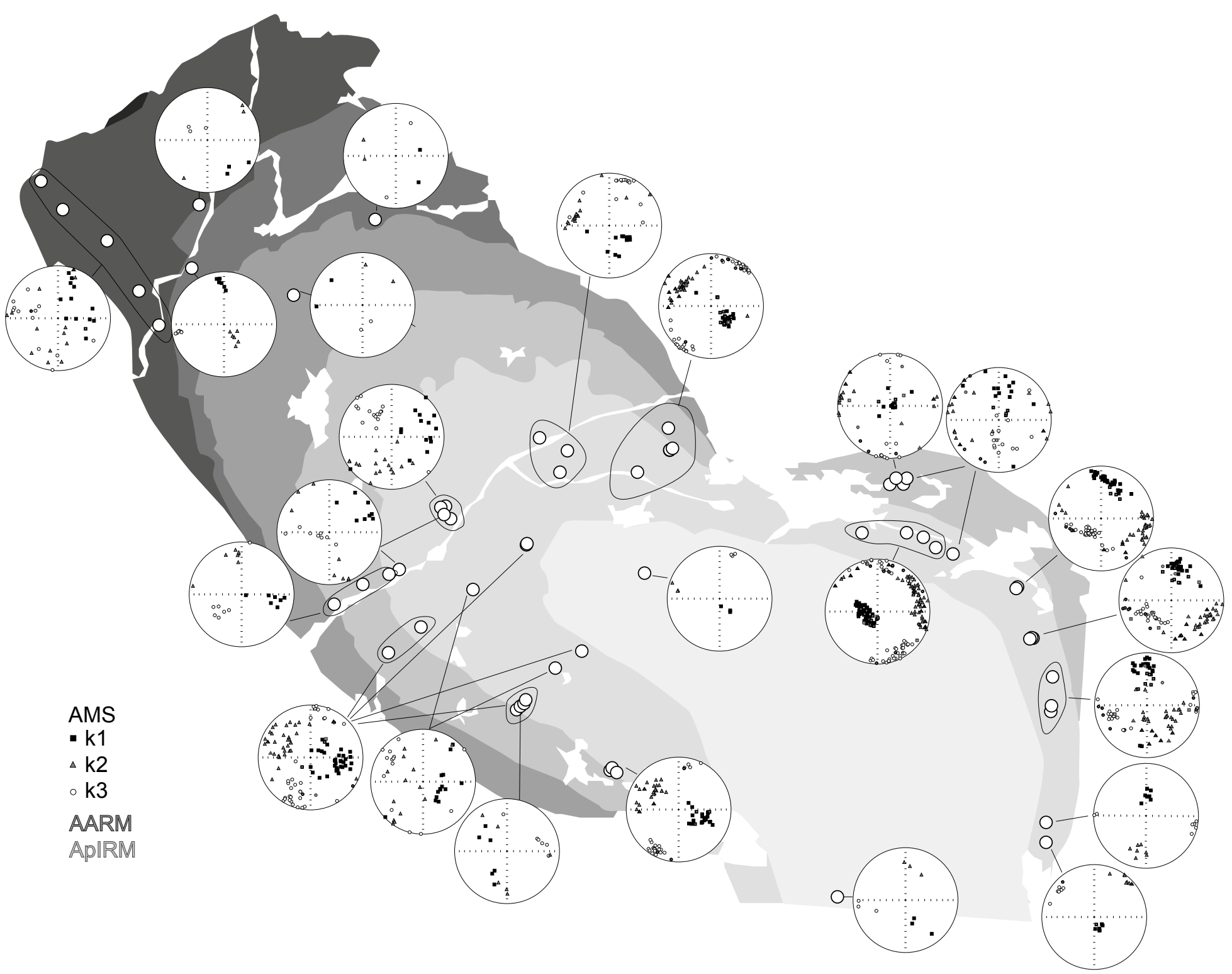

Figure 8: Lower hemisphere equal-area stereoplots showing the directions of principal AMS and anisotropy of remanence axes. cf Figure B, Supplementary Material, for a complete map with separate stereoplots for each site. 

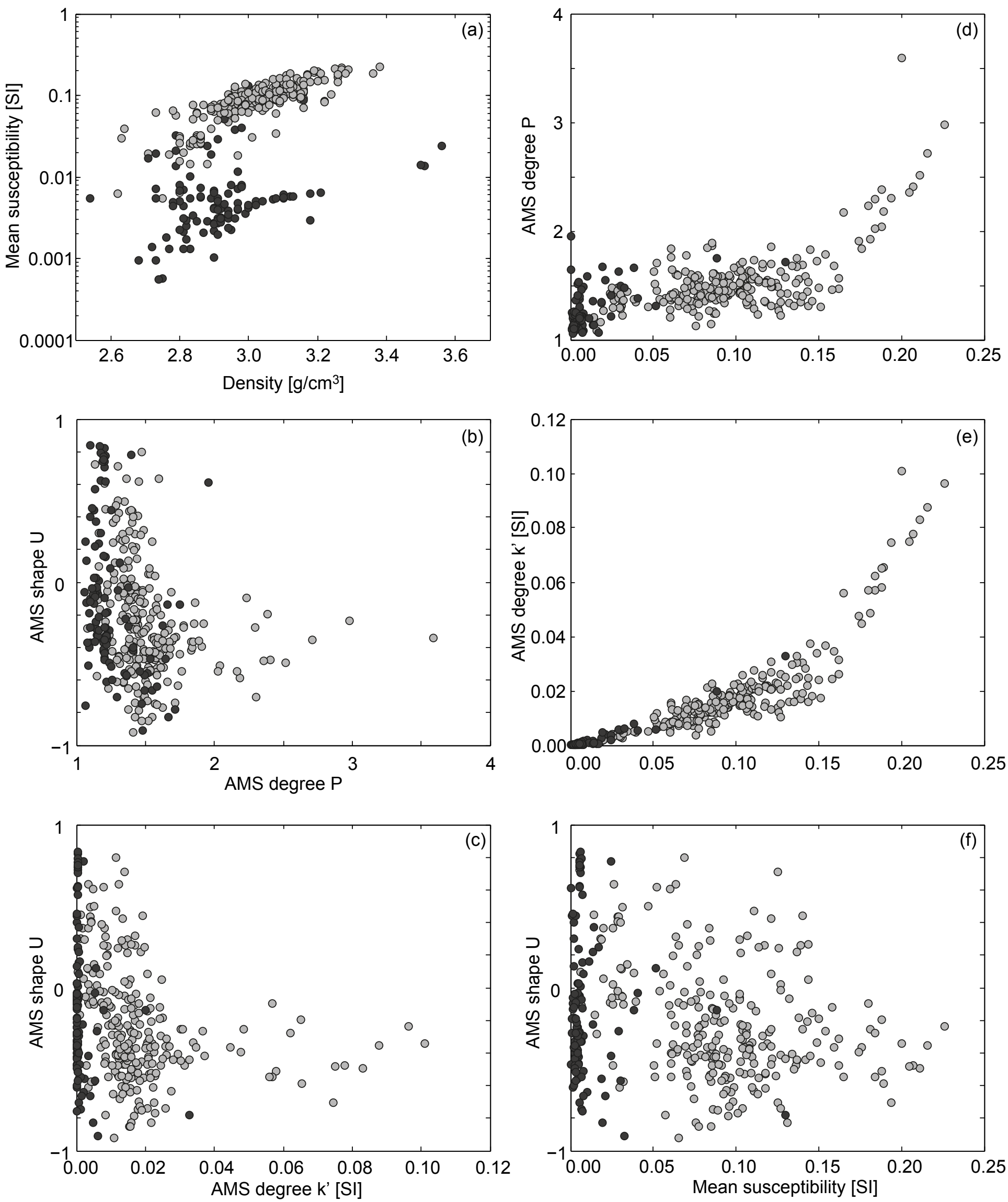

Figure 9: (a) Mean magnetic susceptibility as a function of density. (b-f) Correlations between mean susceptibility and various anisotropy parameters. Black symbols indicate specimens from a or c layers, i.e. containing mainly hemo-ilmenite as ferromagnetic mineral, and grey symbols refer to specimens from the $b, d$-f layers and mangerite, whose magnetic susceptibility is dominated by magnetite. 
Figure 10 , color for online

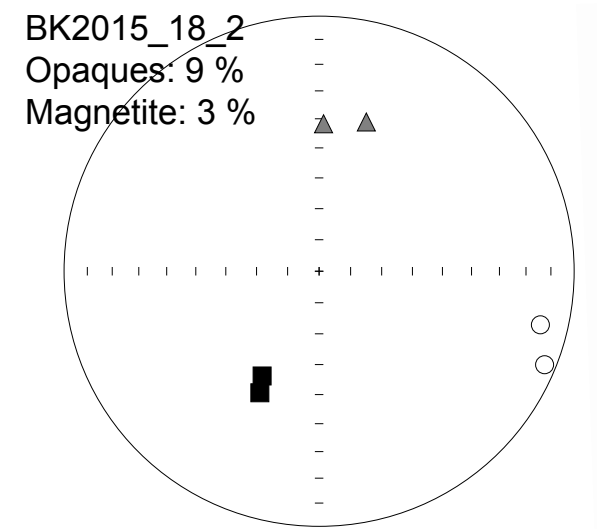

BK2015_24_2

Opaques: $5 \%$

Magnetite: $0.3 \%$

\section{BK2015_7_5}

Opaques: $10 \%$

Magnetite: $3 \%$
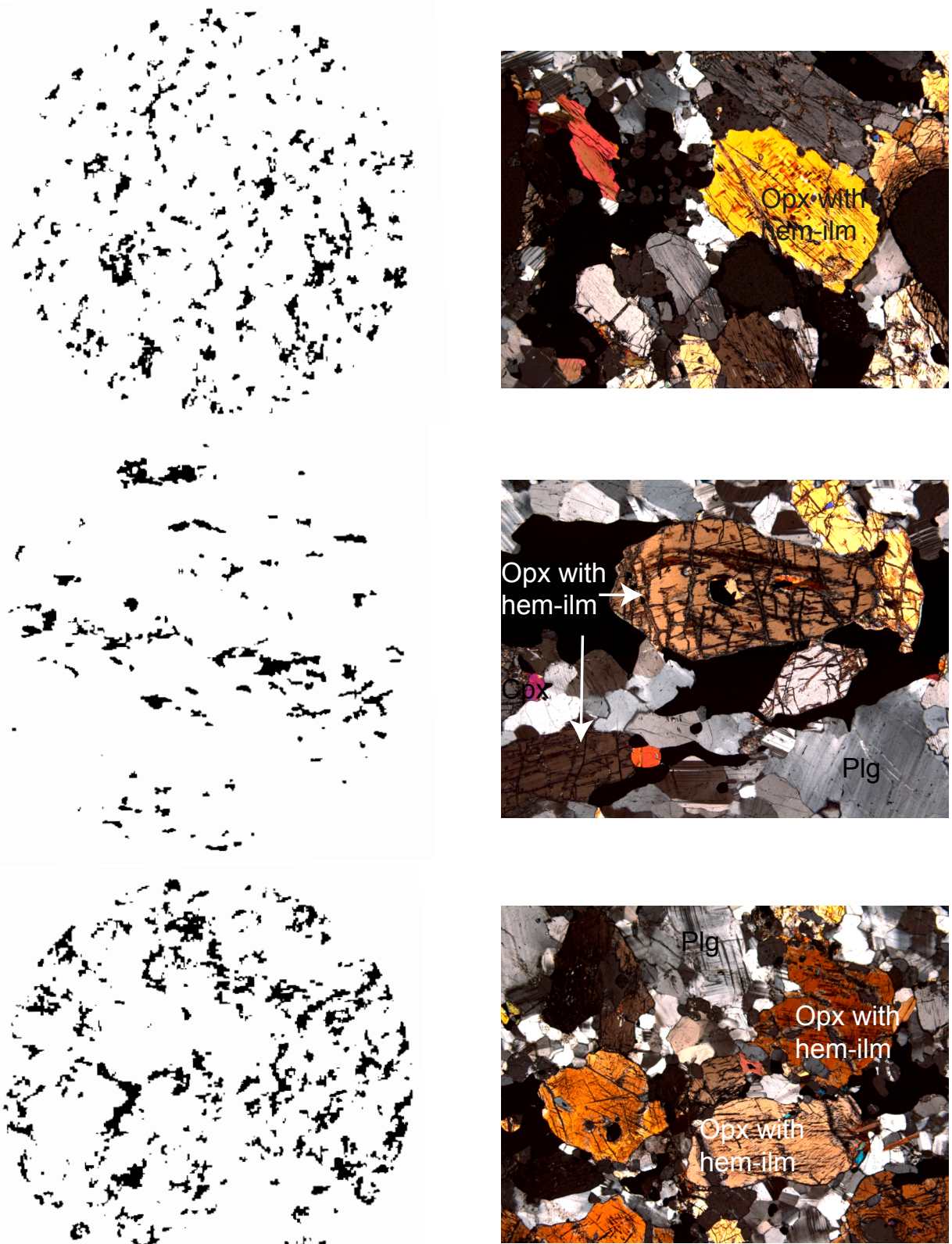

Figure 10: Comparison of AMS and shape and distribution of opaque grains for three representative specimens (left and middle). The minimum susceptibility is normal to bands of opaque grains and their preferred elongation; the maximum susceptibility is parallel to the bands and preferred elongation. Area \% opaques as determined from image analysis; vol.\% magnetite from mean magnetic susceptibility and Clark's (1997) formula. Diameter of thin sections $2.5 \mathrm{~cm}$. (right) Thin section photographs to show mineralogy of the corresponding samples, cross-polarized light. 


\section{Figure 10, bw for print}

BK2015_18_2

Opaques: $9 \%$

Magnetite: $3 \%$

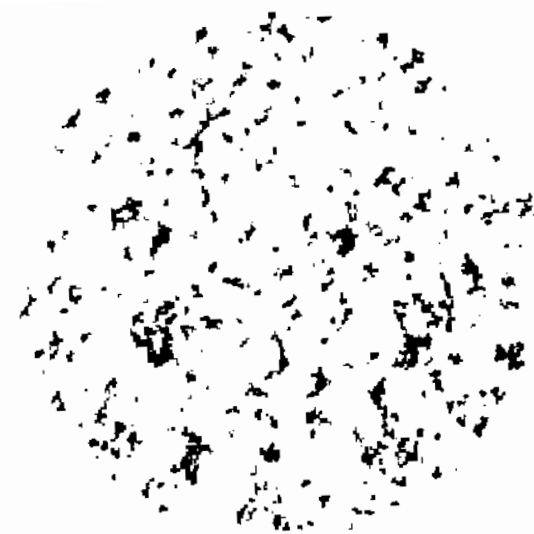

BK2015_24 2

Opaques: $5 \%$

Magnetite: $0.3 \%$

\section{BK2015_7_5}

Opaques: $10 \%$

Magnetite: $3 \%$

-

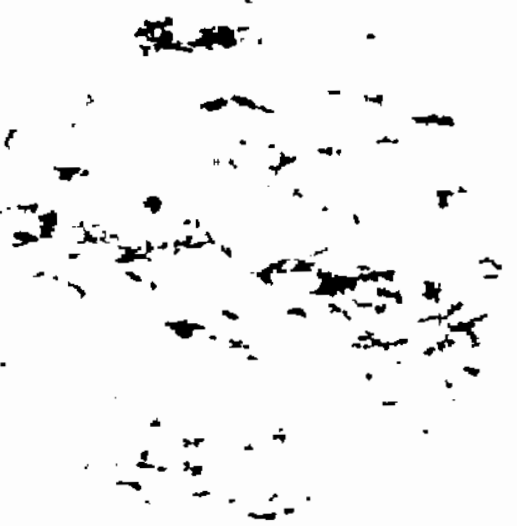

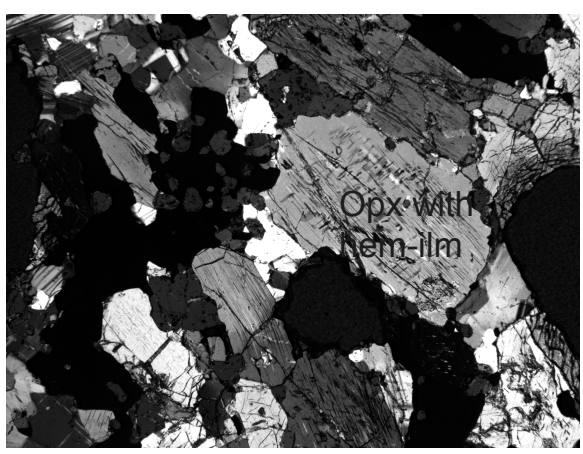
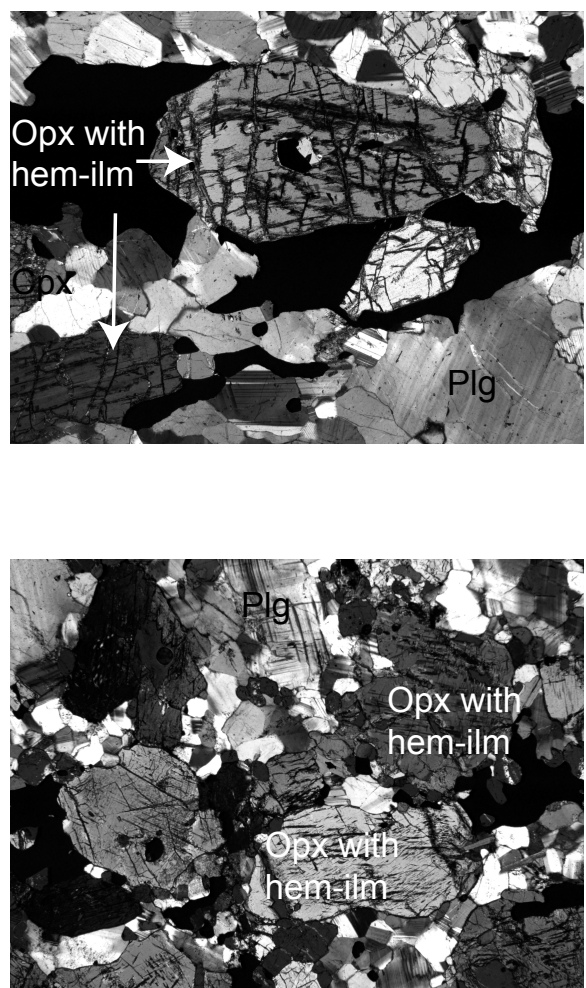

Figure 10: Comparison of AMS and shape and distribution of opaque grains for three representative specimens (left and middle). The minimum susceptibility is normal to bands of opaque grains and their preferred elongation; the maximum susceptibility is parallel to the bands and preferred elongation. Area \% opaques as determined from image analysis; vol.\% magnetite from mean magnetic susceptibility and Clark's (1997) formula. Diameter of thin sections $2.5 \mathrm{~cm}$. (right) Thin section photographs to show mineralogy of the corresponding samples, cross-polarized light. 
Figure 11, qodgerteriaplisiên, syncline

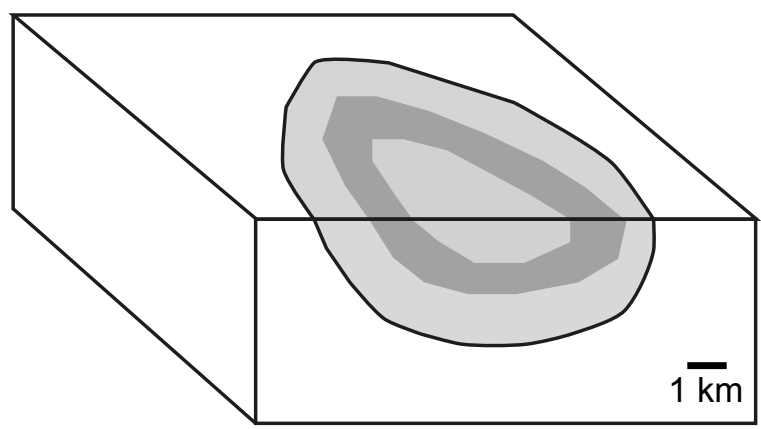

Preferred mineral orientation and arrangement

Magnetocrystalline anisotropy

Opx

(001) Cpx Hem-ilm
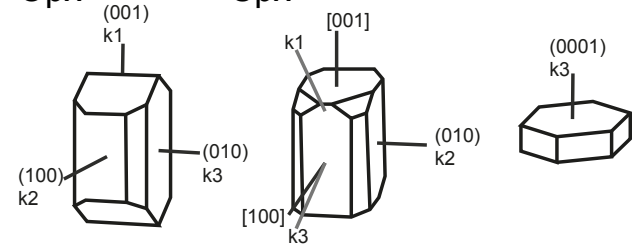

$1 \overline{\mathrm{km}}$
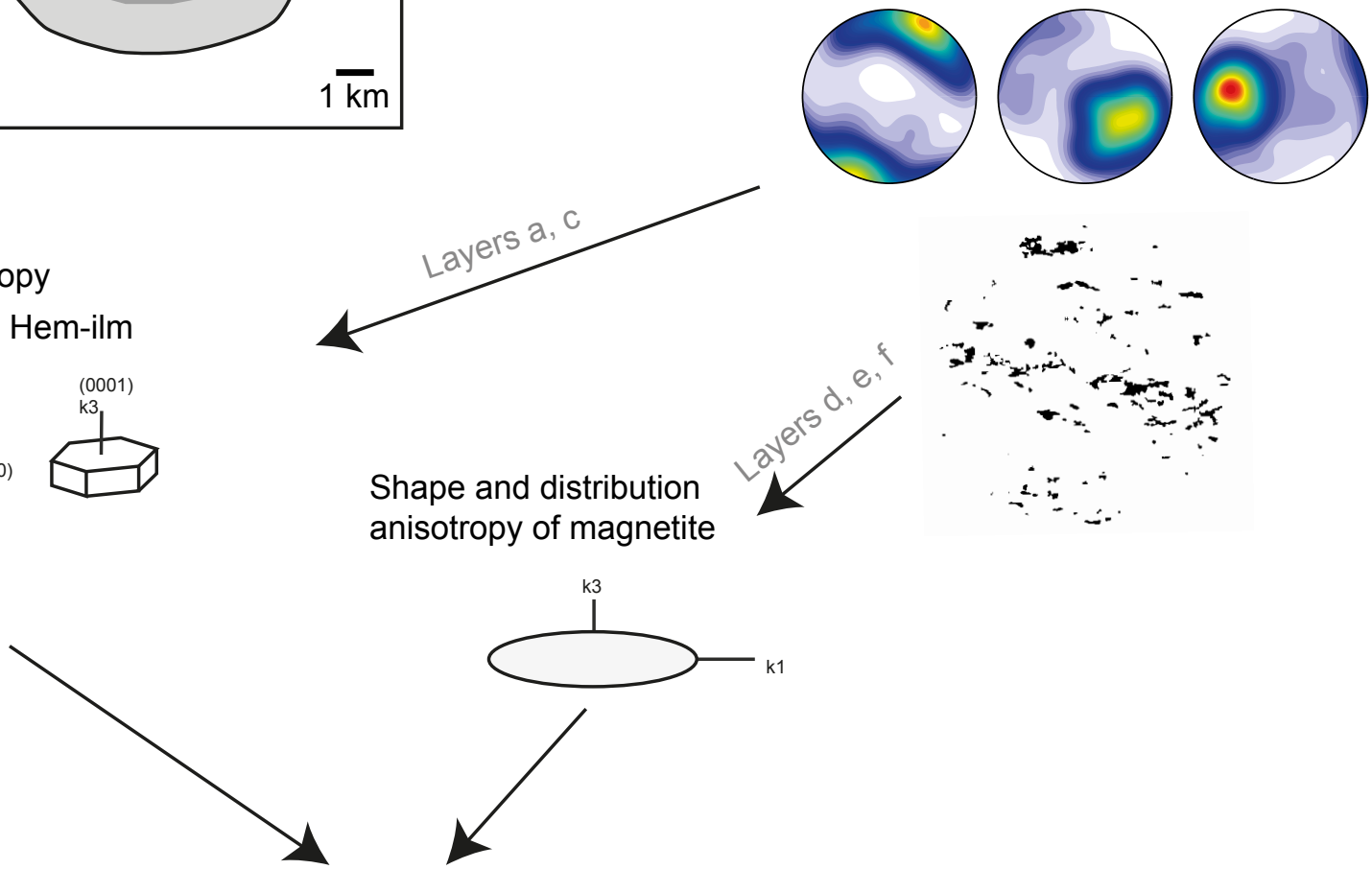

Shape and distribution anisotropy of magnetite

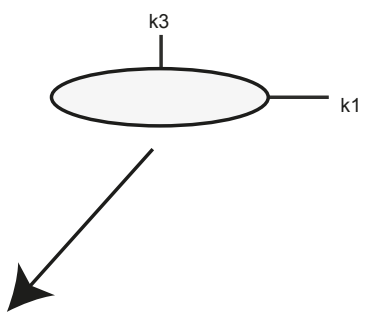

Observed magnetic fabric
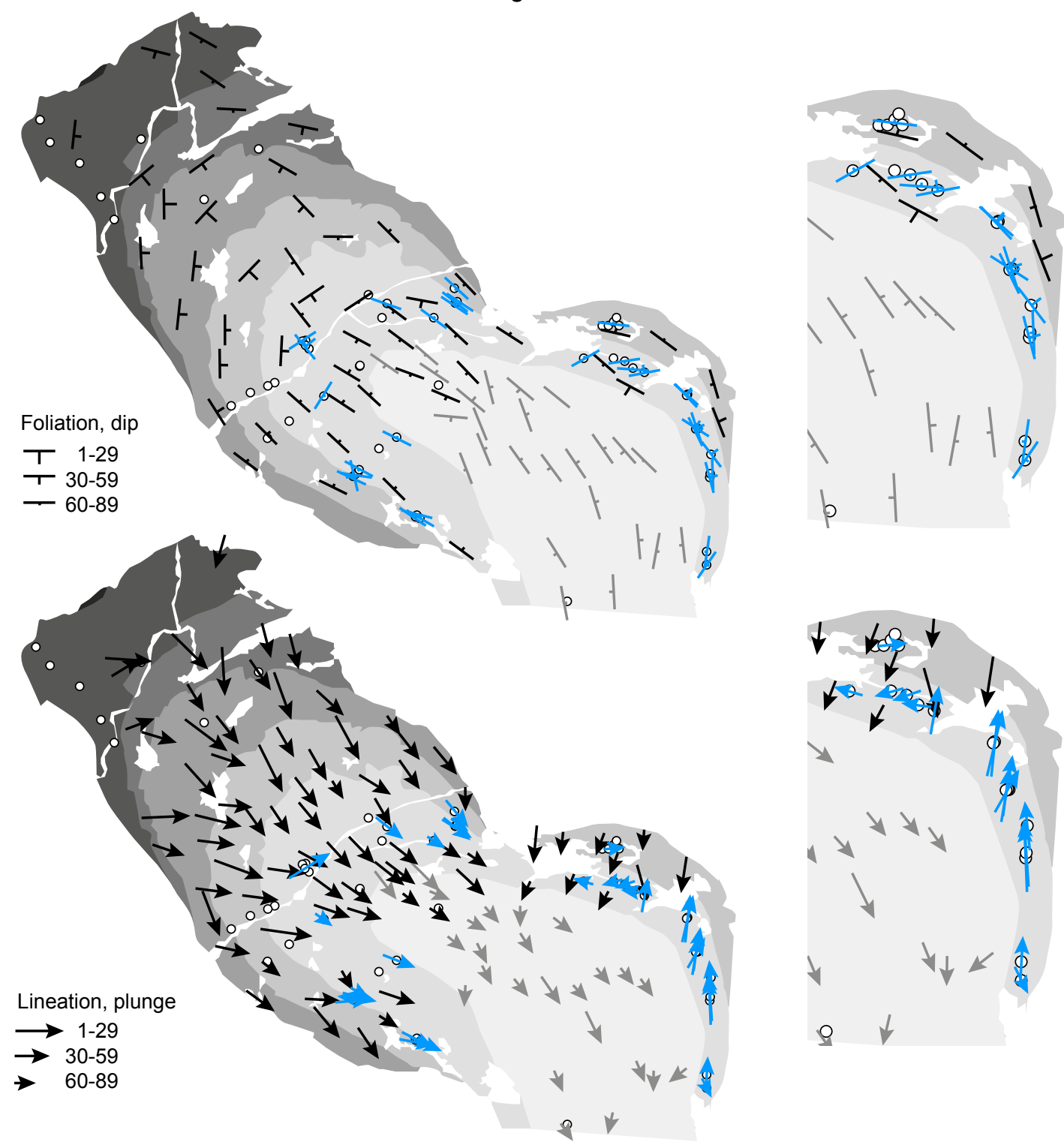

Figure 11: Schematic sketch of processes and mineral properties causing the magnetic fabric (top). (bottom) Mean foliation and lineation of previous petrofabric and low-field AMS studies (blackPaludan et al. 1994, grey - Bolle et al. 2000) and magnetic foliation and lineation from low-field AMS of the present study (blue); site means of at least 5 specimens, and sufficiently small confidence angle). Insets on the right show blow-ups of the northeastern part of the BKS. 
Figure 11, tewytererintusion, syncline

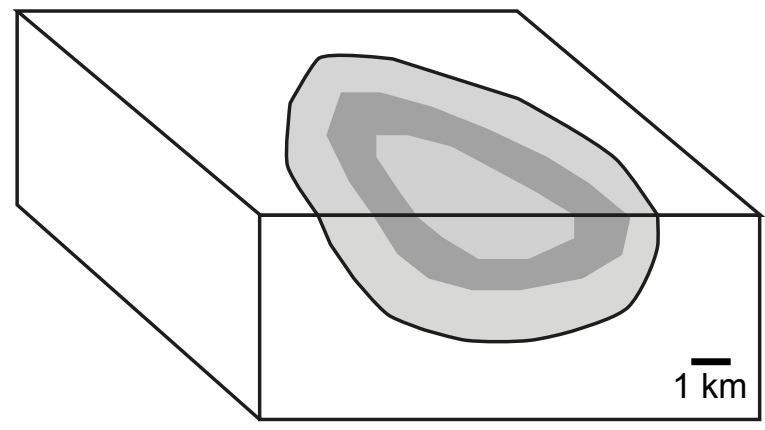

Preferred mineral orientation and arrangement

Magnetocrystalline anisotropy

Opx

Cpx Hem-ilm
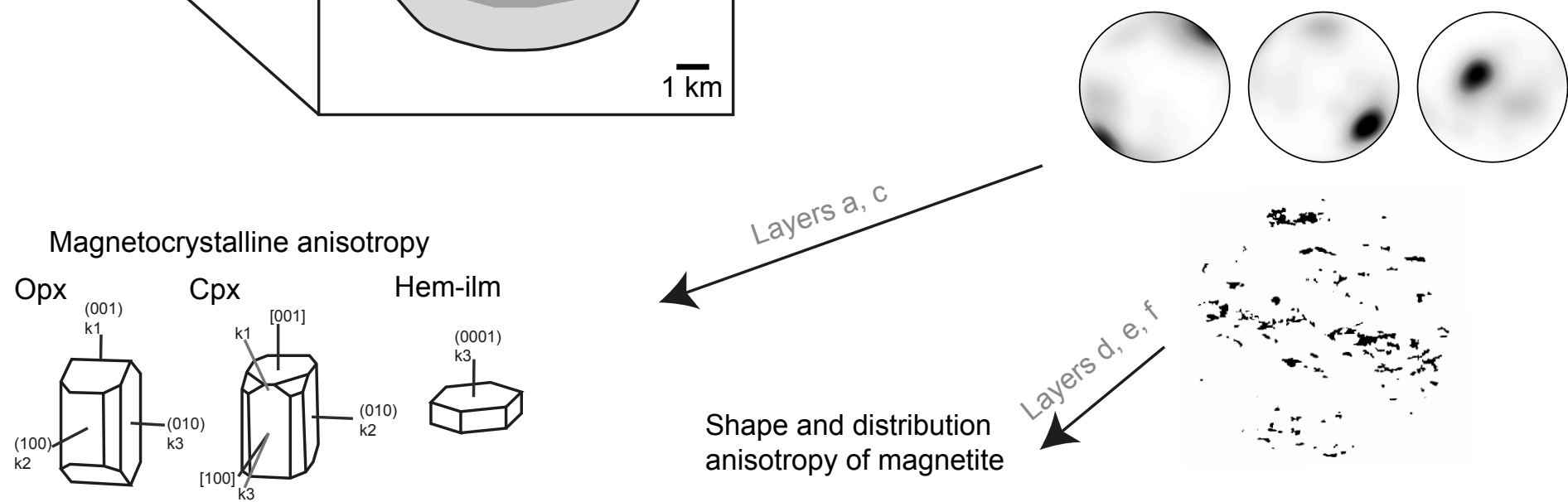

Shape and distribution anisotropy of magnetite
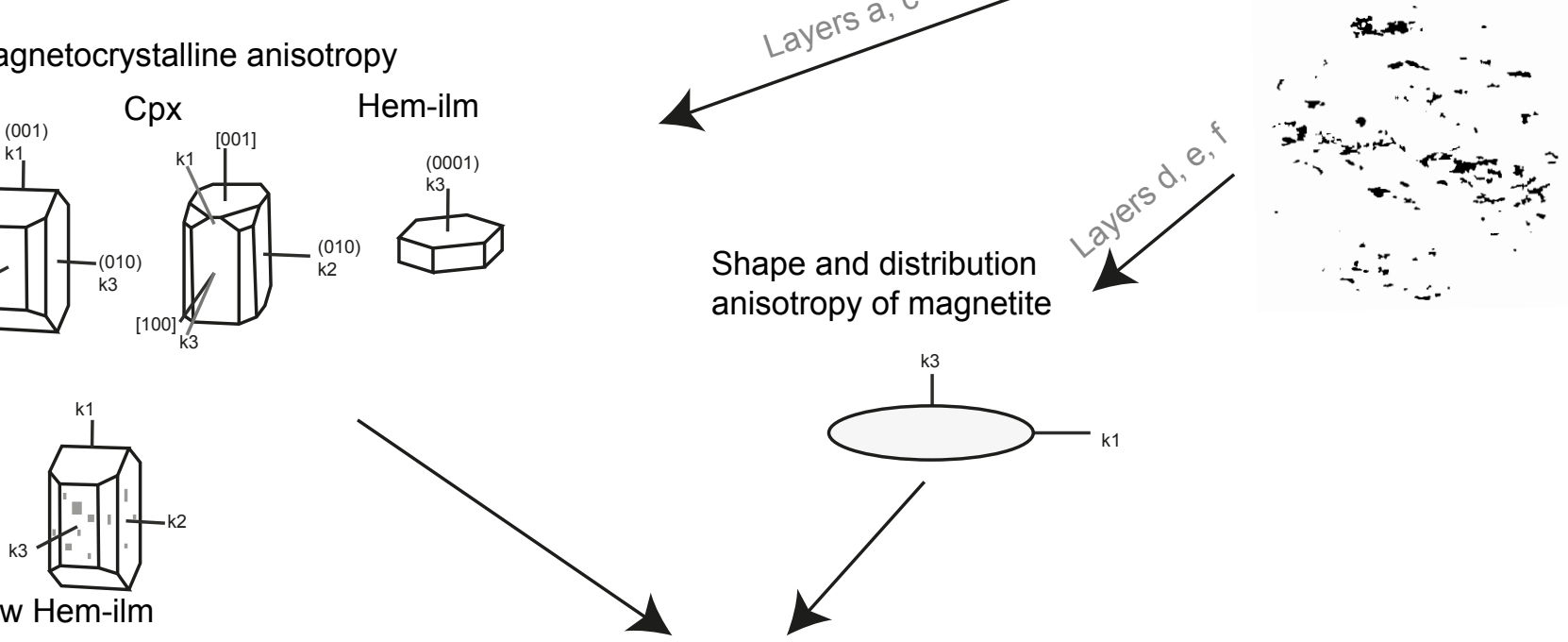

Observed magnetic fabric
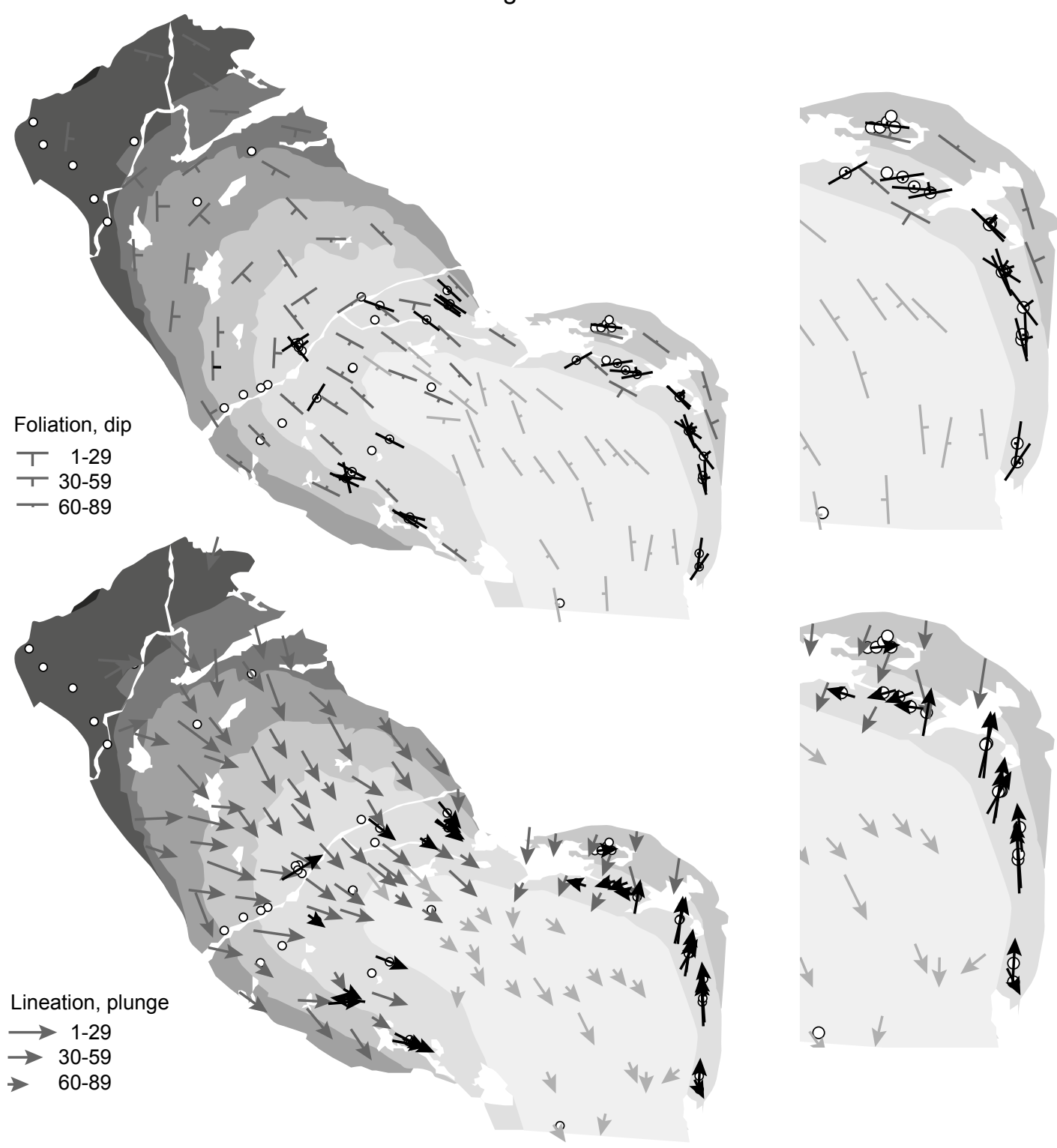

Figure 11: Schematic sketch of processes and mineral properties causing the magnetic fabric (top). (bottom) Mean foliation and lineation of previous petrofabric and low-field AMS studies (dark grey Paludan et al. 1994, grey - Bolle et al. 2000) and magnetic foliation and lineation from low-field AMS of the present study (black); ite means of at least 5 specimens, and sufficiently small confidence angle). Insets on the right show blow-ups of the northeastern part of the BKS. 

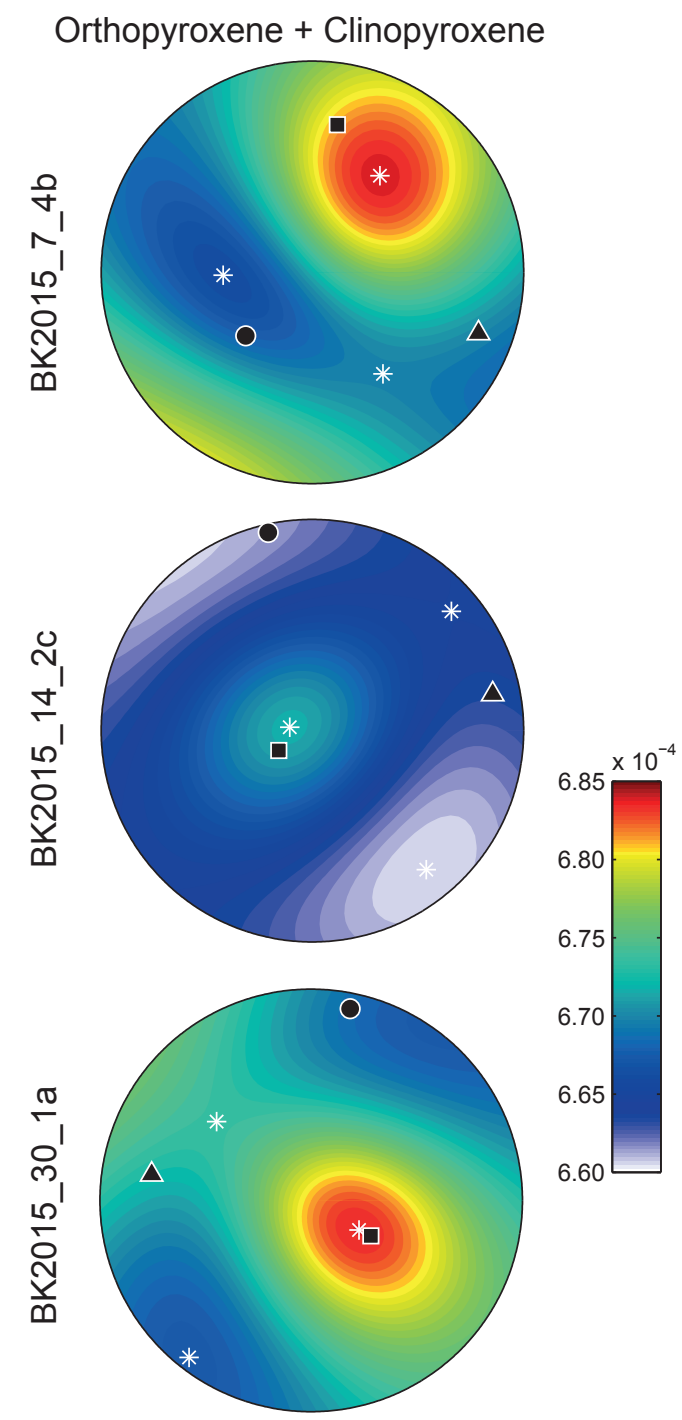

Figure 12: Lower hemisphere stereoplots showing modelled (white stars) and measured (black symbols: squares, triangles and dots are maximum, intermediate and minimum axes, respectively) principal magnetic susceptibility axes for representative specimens. 
Figure 12, bw for print

Orthopyroxene + Clinopyroxene
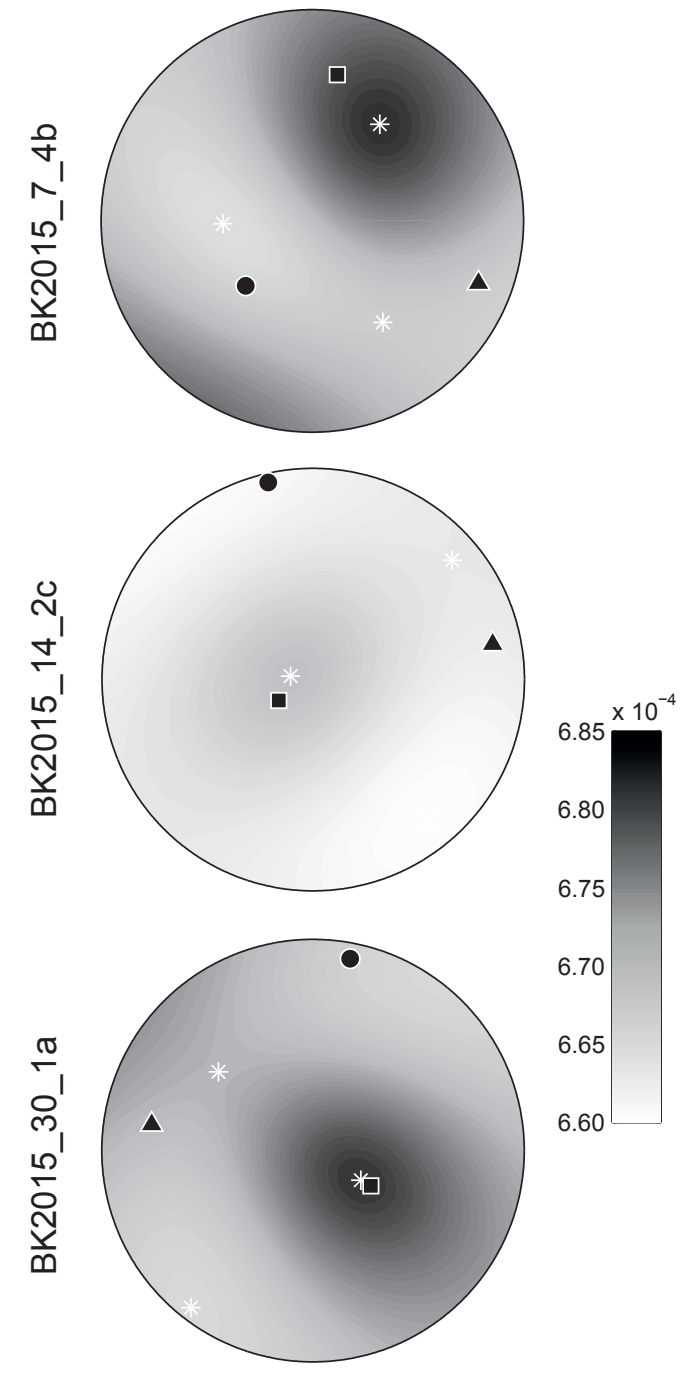

Figure 12: Lower hemisphere stereoplots showing modelled (white stars) and measured (black symbols: squares, triangles and dots are maximum, intermediate and minimum axes, respectively) principal magnetic susceptibility axes for representative specimens. 